\title{
Pitch accent alignment in Romance: primary and secondary associations with metrical structure*
}

\author{
Pilar Prieto ${ }^{+}$, Mariapaola D'Imperio!, and Barbara Gili Fivela ${ }^{\wedge}$
}

${ }^{+}$Institució Catalana de la Recerca i Estudis Avançats (ICREA) and Universitat

Autònoma de Barcelona (UAB), Spain

! Laboratoire Parole et Langage, UMR 6057 CNRS, Aix-en-Provence, France

^ Universitá degli Studi di Lecce, Italy

Submitted for the Special Issue on Intonation in Language Varieties, ed. by Paul Warren.

Running head: Pitch accent alignment in Romance

Corresponding author's full address:

Pilar Prieto

Departament de Filologia Catalana

Universitat Autònoma de Barcelona

Bellaterra 08193

Barcelona (Catalunya)

Spain

\footnotetext{
*The article develops some materials and ideas presented by the first author at the Workshop on Intonation in language varieties organized by $\mathrm{P}$. Warren and P. Vermillion as a Satellite Meeting to the 15th International Congress of Phonetic Sciences (Barcelona, August 2003) and at the 2004 ESF Workshop on Typology of Tone and Intonation (Cascais, April 2004). We are grateful to the audience in those workshops, and especially to Amalia Arvaniti, Mary Beckman, and Sónia Frota for useful feedback. Special thanks go to Gorka Elordieta, José Ignacio Hualde, Giovanna Marotta and Carlos Gussenhoven for their comments and suggestions on a first draft of the paper. Finally, we are really grateful to the editor of this volume, Paul Warren, and the two reviewers, Sónia Frota and Bob Ladd, for their comments, which have helped to greatly improve the quality of the paper. All remaining errors are of course ours. This research was funded by grants 2002XT-00032 and 2001 SGR 00150 from the Generalitat de Catalunya and BFF2003-06590 and BFF2003-09453-C02-C02 from the Ministry of Science and Technology of Spain to the first author and by grant 0220244 (ACI Jeune Chercheur) from the Ministry of Research of France to the second author.
} 


\section{Abstract}

The article describes the contrastive possibilities of alignment of high accents in three Romance varieties, namely, Central Catalan, Neapolitan Italian, and Pisa Italian. The Romance languages analyzed in this article provide crucial evidence that small differences in alignment in rising accents should be encoded phonologically. To account for such facts within the AM model, the article develops the notion of 'phonological anchoring' as an extension of the concept of secondary association originally proposed by Pierrehumbert \& Beckman (1988), and later adopted by Grice (1995), Grice, Ladd \& Arvaniti (2000) and others to explain the behavior of edge tones. The Romance data represent evidence that not only peripheral edge tones seek secondary associations. We claim that the phonological representation of pitch accents should include two independent mechanisms to encode alignment properties with metrical structure: (1) encoding of the primary phonological association (or affiliation) between the tone and its tone-bearing unit; and (2), for some specific cases, encoding of the secondary phonological anchoring of tones to prosodic edges (moras, syllables and prosodic words). The Romance data described in the article provide crucial evidence of moraedge, syllable-edge, and word-edge $\mathrm{H}$ tonal associations.

Key words: tonal alignment, primary and secondary association of tones, phonological representation of pitch accents. 


\section{O. INTRODUCTION}

The topic of this article is the relation between phonological association and phonetic alignment of tones. The starting point is provided by the autosegmental-metrical (AM) approach to intonation, which during the last decades has developed an explicit phonological representational approach that has been applied to a variety of languages (Liberman 1975, Pierrehumbert 1980, Pierrehumbert \& Beckman 1988, Beckman \& Pierrehumbert 1988, Ladd 1996, among many others). Even though the AM representational proposal has met with considerable success in accounting for melodic patterns in a variety of languages, the literature on tonal representation points to a few phenomena that resist a transparent analysis. Some of these phenomena have to do with the metrical part of the model, namely, with the concept of starredness and the standard interpretation of the relationship between phonological association and phonetic alignment. First, it has been claimed that the theoretical concept of starredness is somewhat unclear and that its definition cannot solely be based on phonetic alignment (Arvaniti, Ladd \& Mennen 2000). Second, and related to this, it has been pointed out that it can be quite difficult to decide between competing AM analyses of bitonal accents and that the same contours can be transcribed in different ways (Grice 1995, Hualde 2003b).

The goal of the paper is twofold. First, to report on the results of three different Romance varieties (Central Catalan, Neapolitan Italian, and Pisa Italian) with regards to the categorical effects induced by tonal alignment in rising accents. ${ }^{1}$ Second, to develop a proposal about the metrical representation of tones in order to encode the alignment differences reported in these languages. We will take as a point of departure 
Pierrehumbert \& Beckman (1988)'s notion of secondary association. The idea of 'double association' was initially proposed and developed in a formal way in their book Japanese Tone Structure and has been recently applied by Grice, Ladd \& Arvaniti (2000), Gussenhoven (2000) and Welby (2003), and others, to explain the behavior of edge accents. The general claim we make is that we need to incorporate two independent mechanisms to account for metrical association of tones in pitch accents. First, the encoding of the primary affiliation between the tone and its tone-bearing unit (indicated through the use of the star notation). Second, and for some specific cases, the encoding of the 'secondary association' or 'phonological anchoring' of tones to metrical edges. A 'secondary association' can be encoded in the phonological representation of pitch accents and can represent distinctive alignment differences with metrical edges. In other words, $\mathrm{H}$ tones can be affiliated to a given metrically strong syllable, but can also be distinctively associated to ends of moras $(\mu])$, syllables $(\sigma])$, or prosodic words $(\omega])$. In our view, the potential specification of secondary associations should be regarded as a refinement of the AM notational device that will help clarify the mapping procedure between phonological representation and the surface alignment of pitch accents.

The tonal alignment possibilities shown by the three Romance varieties discussed in this article represent crucial evidence both in favor of the distinctive function of $\mathrm{H}$ alignment and in favor of the idea that alignment properties with metrical edges have to be specified phonologically for some pitch accents. Our proposal is developed on the basis of Catalan and it is subsequently applied to the two Italian varieties. First, Catalan displays a three-way phonological distinction between rising accents that is not transparently accounted for with the standard assumptions of the AM framework, namely, rising accents with aligned peaks, rising accents with delayed peaks and 
posttonic rises. ${ }^{2}$ The Italian varieties show that small temporal $\mathrm{H}$ alignment differences within the syllable can trigger contrasts in pitch accent category. For example, Gili Fivela $(2002,2004)$ reports that peaks for broad focus and narrow (contrastive) focus differ, among other things, in the relative position of the peak within the syllable: while in a broad focus accent the F0 maximum is reached later in the syllable, in a contrastive interpretation the peak is reached earlier within the syllable. On the other hand, D'Imperio and House (1997) and D'Imperio (2000, submitted) found that in Neapolitan Italian later alignment of F0 peaks crucially distinguishes yes/no questions from statements. She asked listeners to choose between interpretations of synthetic stimuli along a continuum and found that question responses were obtained categorically with later synchronization of peaks within the syllable. These findings support the idea that in both varieties earlier/later synchronizations of $\mathrm{H}$ within the syllable can differentiate the meaning of the utterance.

The paper is organized as follows. In section 1 we introduce the relevant theoretical background about the AM approach to intonational phonology, concentrating on the notion of starredness and the standard view of the relationship between phonological association and phonetic alignment. In section 2 we present the facts about the contrasting alignment possibilities in Catalan. In section 3 we develop an analysis approach in order to capture the Catalan alignment differences in a more transparent way. In this section, we argue in favor of clarifying the theoretical status of starredness and secondary associations to metrical edges in the phonological representation of pitch accents. Section 4 presents relevant examples of contrastive alignment in Neapolitan Italian supporting secondary association of starred tones to moraic positions within the syllable. Finally, section 5 describes the contrasting pitch patterns found in Pisa Italian 
which are relevant for the discussion, and illustrates how they can be analyzed using the idea of secondary association of starred tones.

\section{ENCODING PHONOLOGICAL ALIGNMENT: THE NOTION OF STARREDNESS}

The framework for the discussion in this article is the autosegmental-metrical (AM) approach to intonation initially developed in Pierrehumbert's (1980) model of English intonation, building on insights by Goldsmith (1975), Liberman (1975) and Bruce (1977) about the treatment of tone from an autosegmental point of view [for an up-todate summary of the developments of the framework, see Ladd 1996 and Gussenhoven 2004, ch. 7]. A key discovery within work on intonation has been the fact that tones in intonational languages are either associated to metrically prominent syllables (pitch accents) or to phrase edges (boundary tones). Many theories of intonational phonology draw a clear distinction between the two, namely, pitch features associated to prominent syllables and pitch features associated to edges of prosodic domains. Within the AM framework, tunes are also decomposed into tones associated to metrically strong syllables and tones associated to edges. The two types of events have thus different association properties: while pitch accents are phonologically associated with prominent syllables, boundary tones are aligned to phrase edges regardless of the stress pattern of adjacent material. Pierrehumbert's original representational analysis defends that the English intonation system consists of an inventory of pitch accents, each consisting of either one or two tones, which can be High $(\mathrm{H})$ and Low $(\mathrm{L})$. Tones are marked with a 
star * to indicate their association with metrically strong syllables and with a percentage diacritic $\%$ to indicate their alignment with the edge of an intonational phrase.

A related discovery is that pitch accent types can be phonologically distinguished by their relative alignment with the stressed syllable. Pierrehumbert (1980) showed that tonal alignment functions contrastively in English and that early aligned pitch accents are phonologically distinct from late aligned pitch accents. Pierrehumbert \& Steele's (1989) results are consistent with the idea that there is a categorical difference between the two accents. They undertook an imitation task with the two intonation patterns of the utterance Only a millionaire illustrated in Figure 1 -throughout the paper, accented syllables will be underlined. The results of the experiment revealed the existance of two separate phonological categories (see also later experiments by Ward \& Hirschberg 1985, Hirschberg \& Ward 1992, among others, which confirmed a clear separation between the two).
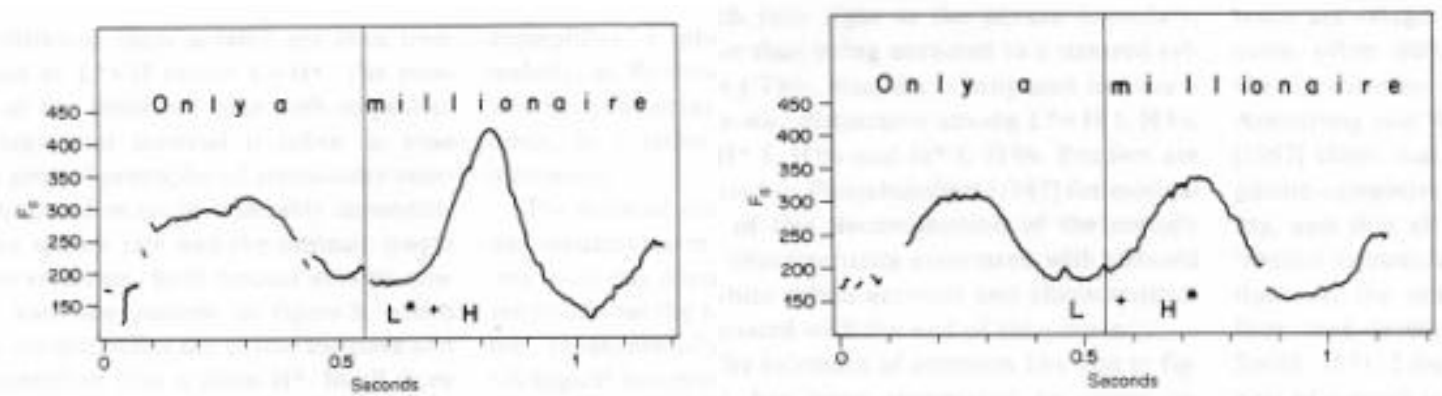

Figure 1. Fundamental frequency contour of the utterance Only a millionaire spoken with two different pitch accents on millionaire: the late-aligned pitch accent, which indicates incredulity or uncertainty (right panel), and the early-aligned pitch pattern, which indicates assertion (left panel). The vertical cursor is placed at the $[\mathrm{m}]$ release in millionaire. [Figures taken from Pierrehumbert \& Steele, 1989, p.182]. 
Pierrehumbert originally proposed that relative alignment in bitonal accents was to be indicated through the use of the star notation *. She proposed an inventory of six pitchaccent shapes for English $\left(\mathrm{H}^{*}, \mathrm{~L}^{*}, \mathrm{H}^{*}+\mathrm{L}, \mathrm{H}+\mathrm{L}^{*}, \mathrm{~L}^{*}+\mathrm{H}, \mathrm{L}+\mathrm{H}^{*}\right)$, some of them encoding alignment differences. For example, the two pitch accents $\mathrm{L}+\mathrm{H}^{*}$ and $\mathrm{L}^{*}+\mathrm{H}$ involve an alignment contrast. The autosegmental representations in (1) capture the fact that the LH shape is aligned differently in the two contrastive pitch accents exemplified in Figure 1. While $\mathrm{L}^{*}+\mathrm{H}$ has a low tone $(\mathrm{L})$ on the stressed syllable and a high tone $(\mathrm{H})$ trailing it, $\mathrm{L}+\mathrm{H}^{*}$ has a high tone on the stressed syllable with a low tone leading it:

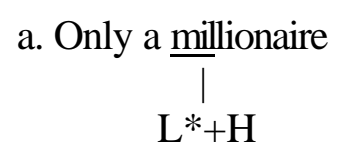

b. Only a millionaire

Thus, the AM phonological representation of pitch accents is encoding 'autosegmental' information (or pitch accent shapes, LH or HL) and 'metrical' information, that is, information about the association of tones with metrical constituents and about the relative alignment with the stressed syllable. As it is, the surface alignment of tones is basically derived from the use of the star notation. The star notation encodes two different things: (1) phonological association with a metrically strong syllable; (2) relative alignment in bitonal accents.

In bitonal accents, it is not completely straightforward which tone in LH or HL accent shapes should be assigned a star. On this issue, Pierrehumbert's original definition states that "a strength relationship is defined on the two tones of bitonal accents: and that it is the stronger tone which lines up with the accented syllable" (Pierrehumbert, 1980, pp. 76-77). From this, it is ambiguous whether the star notation * is indicating 
phonetic alignment between the tonal feature and the stressed syllable or just a more 'loose' phonological association. Similarly, Pierrehumbert \& Beckman (1988, p. 234) note that "the * diacritic marks which tone of a bitonal accent is aligned with the stress". Arvaniti, Ladd \& Mennen (2000, p. 120) state that "phonetically this use of the star is to be interpreted as signifying that the starred tone is aligned in time with the stressed syllable." In subsequent work, one of the most common interpretations of the star notation is that the starred tone is phonetically aligned with the stressed syllable and thus a temporal alignment between the tone and its tone-bearing unit is expected. That is, while an $\mathrm{L}+\mathrm{H}^{*}$ pitch accent should have the peak aligned with the accented syllable, $\mathrm{L}^{*}+\mathrm{H}$ should have the $\mathrm{L}$ tone aligned with the accented syllable. Thus most recent language-particular analyses take the alignment with the syllable as a strong cue to association with it and expect that the $*$ is aligned with the syllable (see Frota, 2000, 2002, for European Portuguese, Jun \& Fougeron, 2000 for French, Grice \& Benzmüller, 1995, Grice et al., 2005a for German, Grice et al., 2005b for Italian, Arvaniti \& Baltazani, 2004, for Greek, Beckman et al. 2002, Face 2001a, Hualde 2002, Sosa 1999, Toledo 2003, for Spanish, among others).

An analysis which assumes a strict correspondence between the star notation and phonetic alignment is the standard Spanish ToBI analysis of prenuclear vs. nuclear rising accents in Peninsular Spanish (see Sosa 1999, Face 2001a, 2001b, Beckman et al. 2002). Figure 2 shows the F0 contour of the broad focus statement Mariana miraba la luna 'Mariana was staring at the moon'. While prenuclear accents are produced as rising pitch accents with late F0 peak alignment, the nuclear pitch accent on luna is produced with an early F0 peak alignment ${ }^{3}$ - throughout the paper, prenuclear accented 
syllables are underlined (Mariana) and nuclear accented syllables appear in underlined capital letters $(\underline{L U n a})$.

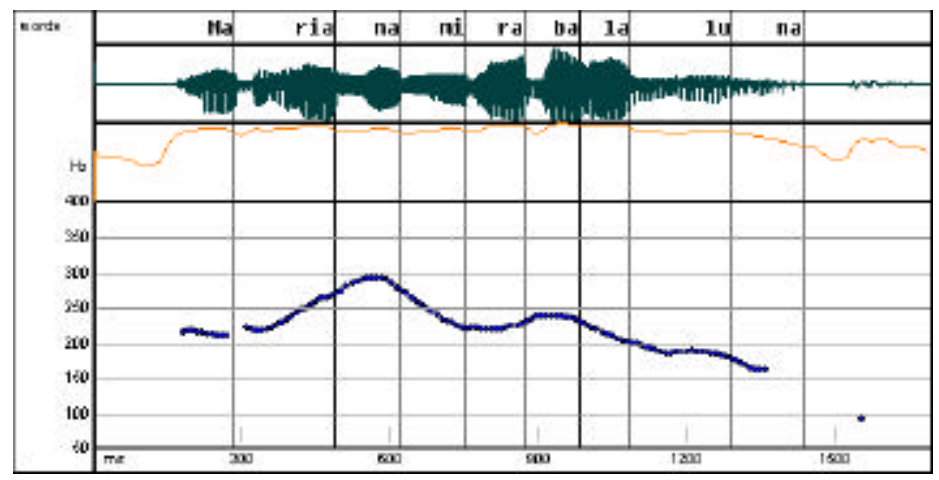

Figure 2. Waveform and fundamental frequency contour of the utterance Mariana miraba la LUna 'Mariana was staring at the moon'.

As stated in (2), the standard analysis assumes that prenuclear accents have the $\mathrm{L}^{*}+\mathrm{H}$ pattern (cf. Mariana and miraba) and that nuclear pitch accents have the $\mathrm{L}+\mathrm{H}^{*}$ pattern (cf. LUna). The star notation is thus indicating that $\mathrm{H}$ is phonetically aligned with the accented syllable.

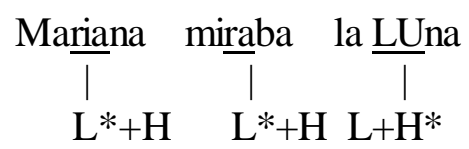

Indeed, such a phonological representation adequately captures the two-way contrast in $\mathrm{H}$ peak alignment between the two Spanish pitch accents. Yet, some problems arise with such a representation if one expects the starred tone to be strictly related to temporal phonetic alignment. First, it should be expected that $\mathrm{L}$ behaves as the mirror image of $\mathrm{H}$, that is, that $\mathrm{L}$ is aligned with the stressed syllable in prenuclear accents and that is not aligned in nuclear accents. Yet, it is a well-known fact that $\mathrm{L}$ valleys in both 
prenuclear and nuclear accents are aligned quite consistently with the onset of the accented syllable (Prieto et al. 1995, Prieto 1998, Face 2001a, among others). In Spanish nuclear accents, typically both $\mathrm{L}$ and $\mathrm{H}$ tone targets are aligned with the stressed syllable (see Figure 2). Thus why is L not incorporated (i.e., not starred) in the nuclear accent? In fact, this is the solution that was adopted by Hualde (2002). In his analysis, Hualde incorporated the syllable-initial $\mathrm{L}$ tone to the phonological definition of the accent, which was defined as $(\mathrm{L}+\mathrm{H})^{*}$, with both tones associated with the stressed syllable. ${ }^{4}$ Yet, doing so means departing from the original notion of starredness as a marker of a metrical strength relationship between two pitch nodes, the strong node and the weak node.

Similar problems arise in the representation of Greek and Neapolitan Italian rising accents. Arvaniti, Ladd \& Mennen (2000:121) present evidence from Greek of the types of problems that arise when we take phonetic alignment to the accented syllable to be the exponent of association of tones to segments. As they note, "we show that there exist pitch accents that are clearly bitonal but in which neither tone is, strictly speaking, aligned with the accented syllable. We argue from this fact that association cannot be based on phonetic alignment in any straightforward way and that a more abstract and rigorously defined notion of starredness is required." In Greek, typically, neither L nor $\mathrm{H}$ are phonetically aligned with the stressed syllable: in most cases, the $\mathrm{L}$ is consistently aligned before the beginning of the accented syllable $(5 \mathrm{~ms}$ on average before the onset), and $\mathrm{H}$ displays more variability and is typically placed in the posttonic syllable. Neapolitan Italian shows a similarly puzzling situation. Namely, the L and $\mathrm{H}$ of both the yes/no question and the narrow focus statement LH pitch-accent rises are aligned with 
the same stressed syllable, as shown here for the word LALla LALla 'Lalla (proper name)' (see Figure 3; for more details, see $\S 4$ below).

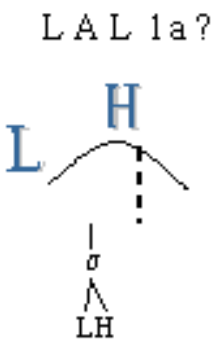

LAL 1 a.

Figure 3. Schematic representation of tonal alignment in the nuclear accent of Neapolitan questions (left) and statements (right). The right boundary of the stressed syllable is marked by a dashed line (from D'Imperio 2000, p. 25).

Thus, Arvaniti, Ladd \& Mennen (2000) conclude that "if alignment is the sole exponent of the association of tones to segments, phonetic variability in this domain becomes a crucial issue when the phonological structure of a bitonal accent is in question." (Arvaniti, Ladd \& Mennen 2000, p. 121). We take it as essentially correct that a one-toone relationship between phonological association and phonetic alignment is difficult to maintain in the current AM model.

Let us now compare the surface alignment of the tones described by the English and Spanish contrast between $\mathrm{L}^{+} \mathrm{H}^{*}$ and $\mathrm{L}^{*}+\mathrm{H}$ (cf. also (1) and (2) and Figures 1 and 2). The four diagrams in Figure 4 illustrate the schematic phonetic realization of both pitch accents with respect to the stressed syllable in English and in Spanish. Even though the two phonological units capture the two-way phonological contrast present in both languages, two different phonetic realizations (or alignment patterns) emerge from the use of the same labels $\mathrm{L}_{+} \mathrm{H}^{*}$ and $\mathrm{L}^{*}+\mathrm{H}$ in English and in Spanish. In fact, English 
$\mathrm{L}+\mathrm{H}^{*}$ corresponds to Spanish $\mathrm{L}^{*}+\mathrm{H}$, while the other two accents have a different interpretation.

\section{$\underline{\text { English }}$}

$\mathrm{L}+\mathrm{H}^{*}$

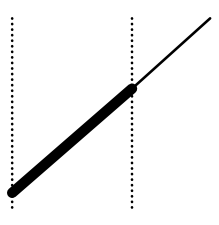

$\mathrm{L}^{*}+\mathrm{H}$

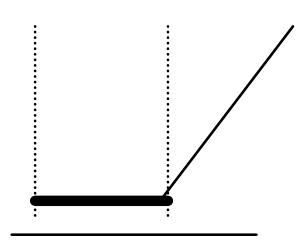

$\underline{\text { Spanish }}$

$\mathrm{L}+\mathrm{H}^{*}$

$\mathrm{L}^{*}+\mathrm{H}$

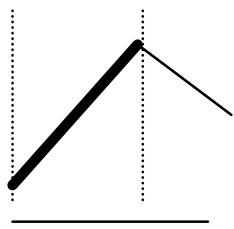

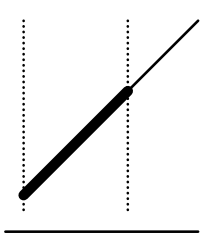

Figure 4. Schematic representation of English and Spanish $\mathrm{L}+\mathrm{H}^{*}$ and $\mathrm{L}^{*}+\mathrm{H}$.

In our view, the reason behind such a transcription difference lies in the ambiguous interpretation of starredness. In the case of Spanish, a more or less strict correspondence between starredness and phonetic alignment is assumed; by contrast, the English labels are not based on a strict binary contrast of alignment, since in both pitch accents L is aligned with the accented syllable and $\mathrm{H}$ with the postaccentual syllable. In relation to the issue of ambiguity, Hualde (2003b, pp. 177-180) notes that there are difficulties in agreeing with a given AM transcription. He gives a very simple example. A Spanish F0 intonation contour like the one shown in (3) (similar to the one shown in Figure 2) can have at least the following three AM transcriptions. Thus a sequence of peaks can be interpreted as a series of rising accents LH (analyses in a and a') or as a series of falling accents HL (analysis in b):

$\underline{\text { Possible AM analyses }}$

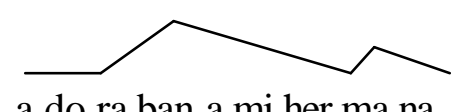

a do ra ban a mi her ma na 


$\begin{array}{llll}\text { a. } & & \mathrm{L}^{*}+\mathrm{H} & \mathrm{L} *+\mathrm{H} \mathrm{L} \% \\ \text { a'. } & & \mathrm{L}^{*}+\mathrm{H} & \mathrm{L}+\mathrm{H}^{*} \mathrm{~L} \% \\ \text { b. } & \% \mathrm{~L} & \mathrm{H}^{*}+\mathrm{L} & \mathrm{H}^{*}+\mathrm{L} \mathrm{L} \%\end{array}$

Analysis (a) postulates two rising accents $\left(\mathrm{L}^{*}+\mathrm{H}\right)$ and a final boundary tone $\mathrm{L} \%$. Analysis (a') is a variant of (a) where the two rising accents are considered to be distinct phonological categories, as in the Spanish standard notation. As Hualde (2003b) contends, the decision between (a) and (a') depends on independent arguments that advocate for contrastiveness between these two pitch accents in the language, and also on phonetic realization grounds. Analysis (b), which is based on Gussenhoven's analysis of comparable facts in Dutch intonation, postulates two falling accents instead of rising accents. As Hualde points out, the decision about the correct analysis will come from extensive analysis of the alignment behavior of the target $\mathrm{LH}$ points as well as from contrastiveness information in the language. ${ }^{5}$

The phenomena described above evidence that even though the AM representations are able to adequately characterize the minimal contrasts in pitch accent types found in different languages, the mapping procedures between phonological representations and the surface alignment of tones (through the use of the star notation) are somewhat unclear. This is because the specific details of the coordination between tones and the segments that are linked to the structural unit are not part of the phonological representation itself. We thus agree with Arvaniti, Ladd \& Mennen's (2000, p. 130) suggestion "that the task for the future is to refine the notion of the phonological association of tones in intonational systems." In the remainder of this paper we will develop an argument in favor of further refining the metrical part of the AM system in a way that the mapping procedure between the phonological representation and the 
surface F0 patterns is obtained in a more transparent way. We claim that the contrastive possibilities of alignment found in Romance languages advocate for a further development of the metrical part of the AM model in the sense that more features of alignment should be incorporated in the phonological representation of pitch accents.

\section{A THREE-WAY PHONOLOGICAL CONTRAST IN RISING ACCENTS: THE CASE OF CATALAN}

This section illustrates with examples the phonological alignment contrasts for rising LH melodies in Catalan. Our goal is to present instrumental evidence showing that Catalan displays a three-way phonological contrast in rising prenuclear accents (in nuclear position, the contrast is binary). The empirical basis for the examples of this section comes from a database of Central Catalan speech collected in recent years and containing the first author's productions and other speakers' productions. These were elicited using a questionnaire which seeks the response of the speaker after presenting him or her with different pragmatic situations (see Prieto 2002a, 2002b, forthcoming b). The three diagrams in Figure 5 summarize the three-way contrast found in rising pitch accents in Catalan: (a) rises with delayed peak, (b) rises with non-delayed peak, and (c) posttonic rises. As we will see, the three surface patterns are clearly contrastive and used in a productive way in different intonation contours found in the language. This

situation contrasts with the two-way alignment difference in rises reported for Peninsular Spanish or English. 

(a) rise with
(b) rise with
(c) posttonic rise

delayed peak

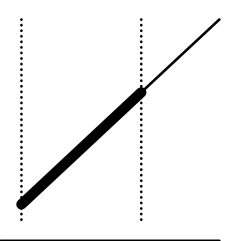

non-delayed peak

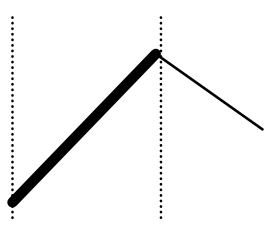

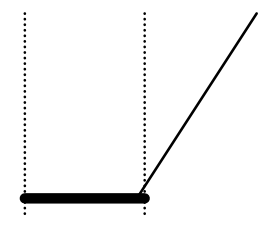

Figure 5. Schematic representation of the three-way contrast in alignment in rising LH pitch accents in Catalan.

The two examples in Figure 6 show the contrast between a rise with a delayed peak and a posttonic rise in prenuclear position. The figure on the left illustrates a prenuclear rise with a delayed peak in the broad focus utterance Volen una NEna 'They want a girl' (see also Figure 6). The figure on the right illustrates the waveform and F0 contour of the polar question Volen una NEna? 'Do they want a girl?'. The first pitch accent of this contour (on Volen) is what we call a posttonic rise: it is phonetically realized as a low tone on the accented syllable (note that the $\mathrm{L}$ inflection starts towards the end of the accented syllable) and it is immediately followed by a rise on the posttonic syllable. ${ }^{6}$ 


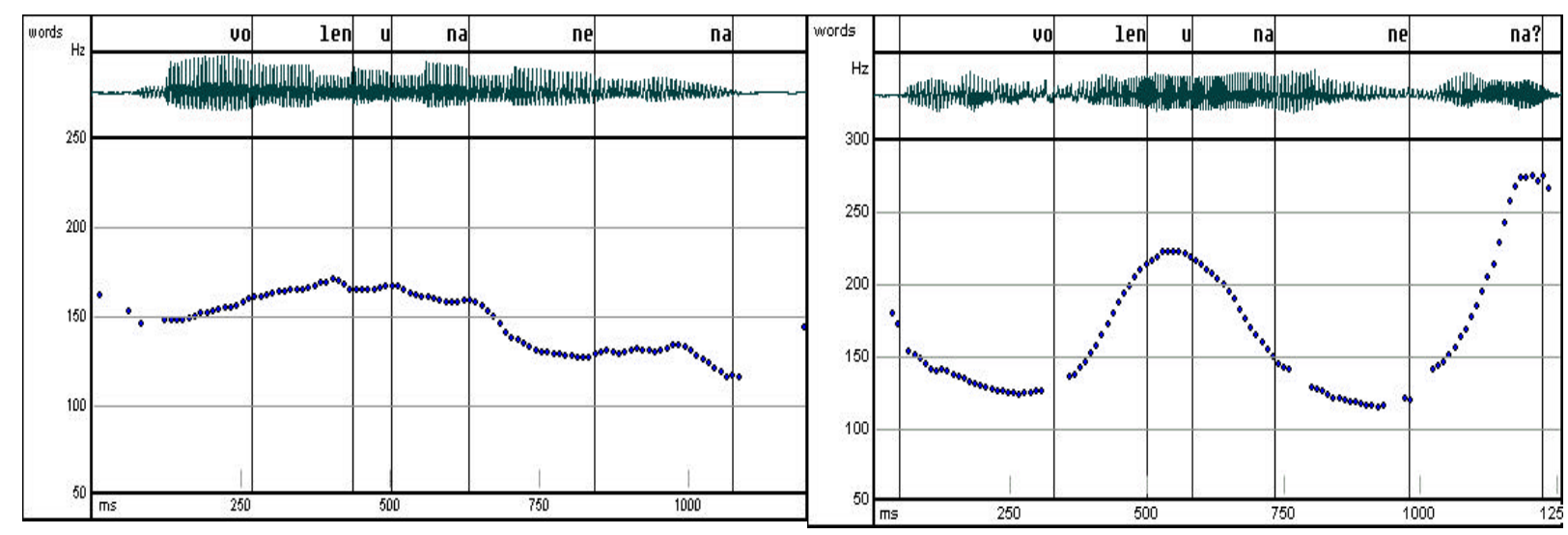

Figure 6 Waveforms and F0 contours of the utterances Volen una NEna 'They want a girl' (broad focus, left panel) and Volen una NEna? 'Do they want a girl?' (polar question, right panel).

The four panels in Figure 7 show the waveforms and F0 traces of the imperative (left panels) and exhortative (right panels) versions of the sentences DIgue-m'ho 'Tell me' (top) and VIne! 'Come' (bottom). The basic distinction between commands and requests (or soft commands) in Catalan is the relative alignment of the rising melody with the accented syllable: while the nuclear accent in imperative sentences is phonetically realized with a peak aligned with the end of the stressed syllable, the nuclear accent in exhortatives is realized as a posttonic rise (that is, a rise that starts at the end of the stressed syllable). 
$\underline{\text { Imperative }}$
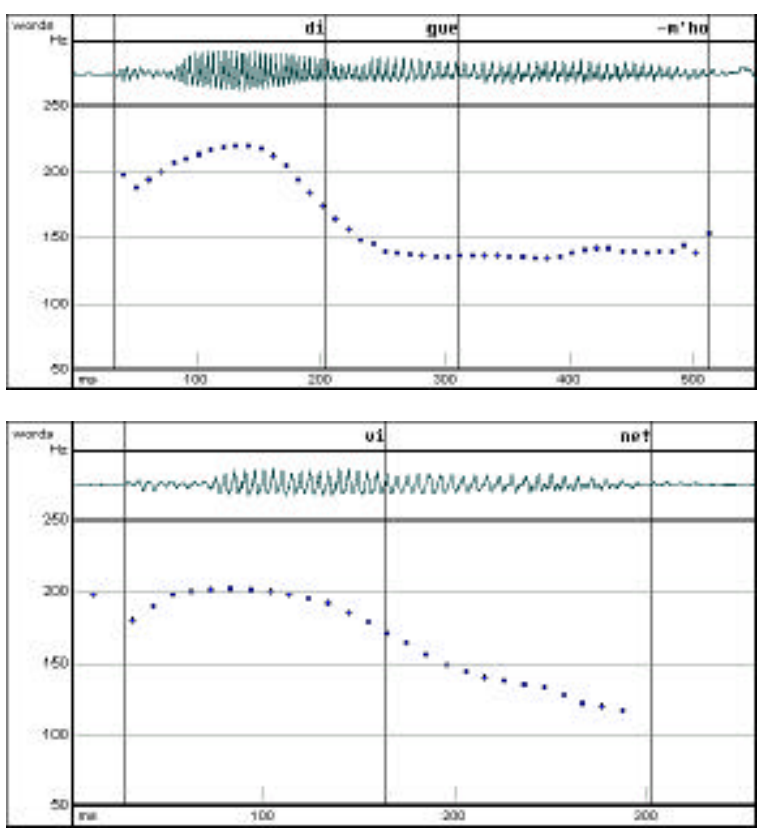

$\underline{\text { Exhortative }}$
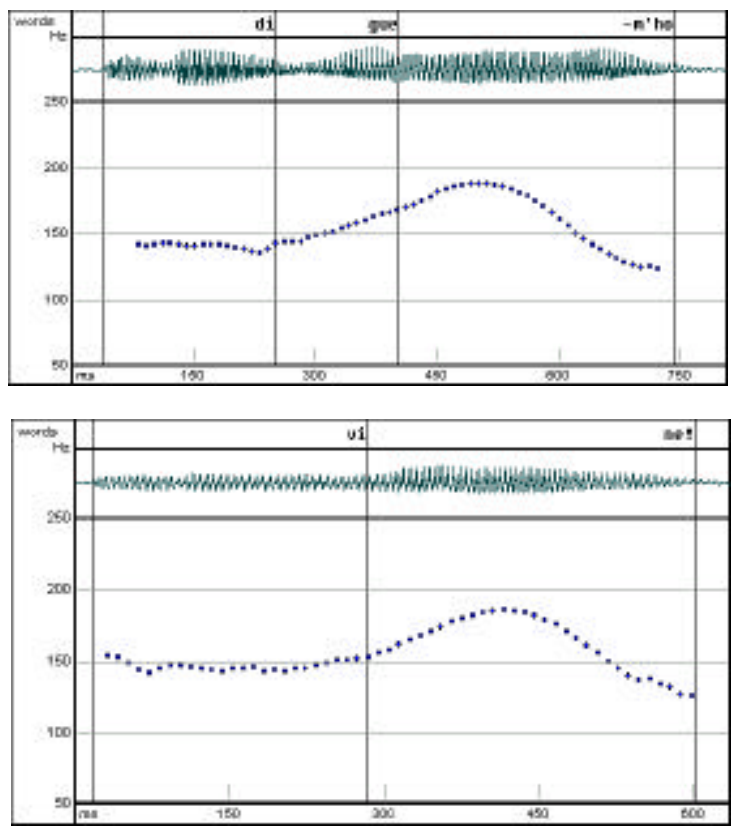

Figure 7. Waveforms and F0 contours of the imperative (left panels) and exhortative

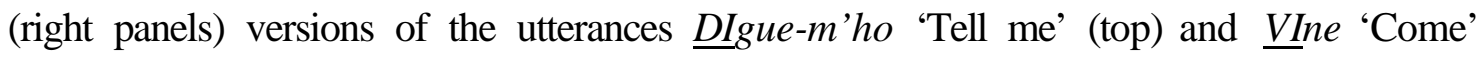
(bottom).

The same contrast between pitch accent alignment in imperative and exhortative utterances is obtained in prenuclear position. The two graphs in Figure 8 show the waveforms and F0 contours of the imperative (left) and exhortative (right) versions of the utterance Dóna-l'hi a la MaIa 'Give it to Mary' —in both sentences, Maria bears the nuclear accent, just strongly downstepped, like many Romance nuclear accents: 


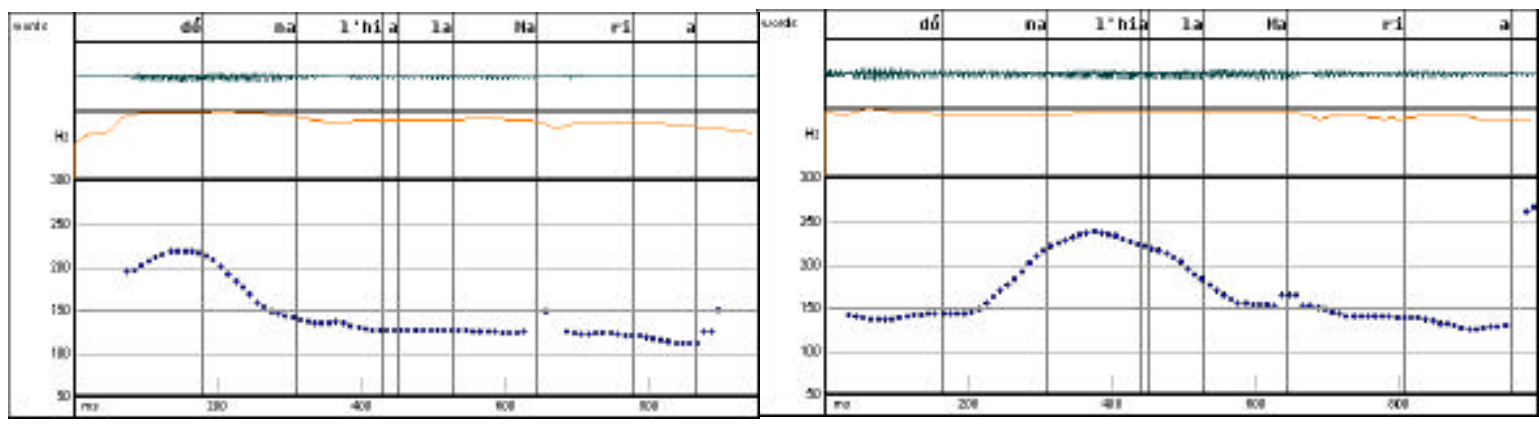

Figure 8. Waveforms and F0 contours of the imperative (left) and exhortative (right)

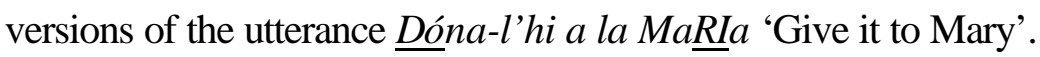

Next, the contrast between delayed vs. non-delayed accents in prenuclear position is obtained between prenuclear pitch accents in broad focus statements and commands. The graph in Figure 9 shows the waveform and F0 contour of the declarative sentence L'hi dóna a la MaIa 'He gives it to Mary' (compare it to imperative utterance Dónal'hi a la MaIa 'Give it to Mary' in Figure 8). The main difference between the two prenuclear rising pitch accents associated to dóna is that the peak is aligned with the right edge of the syllable in the imperative utterance and is delayed in the statement.

$\underline{\text { Statement }}$

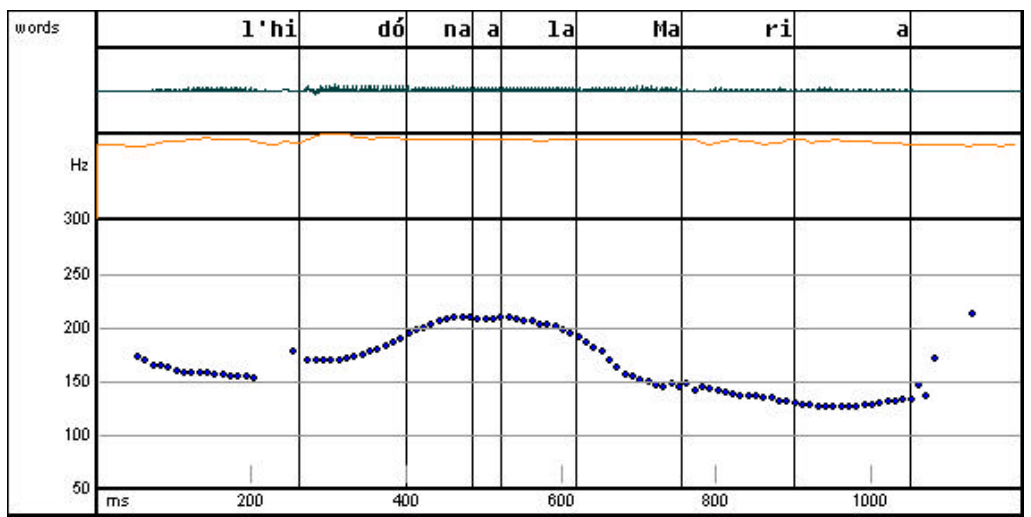

Figure 9. Waveform and F0 contour of the declarative sentence L'hi dóna a la MaIa 'He gives it to Mary'. 
In addition, the two F0 contours in Figure 10 illustrate the contrast between a broad focus statement (top figure) and a narrow focus statement (bottom figure). Instrumental inspection of the two pitch accents on Marina reveals that one of the differentiating features between the two pitch accents is the alignment of the $\mathrm{H}$ peak: while the prenuclear peak in broad focus statements is typically aligned after the stressed syllable, $^{7}$ in narrow focus statements the peak is aligned with the end of the accented syllable (see Prieto 2002a, 2002b and Estebas-Vilaplana 2001). As is well-known, Spanish contains a similar contrast between pitch accents in broad-focus and narrowfocus statements (see de la Mota 1995, Face 2001a, 2001b, and Hualde 2002). This situation is also reflected in the prenuclear $\mathrm{H}^{*}$ vs. the nuclear $\mathrm{L}+\mathrm{H}^{*}$ of narrow focus statements in Neapolitan Italian.
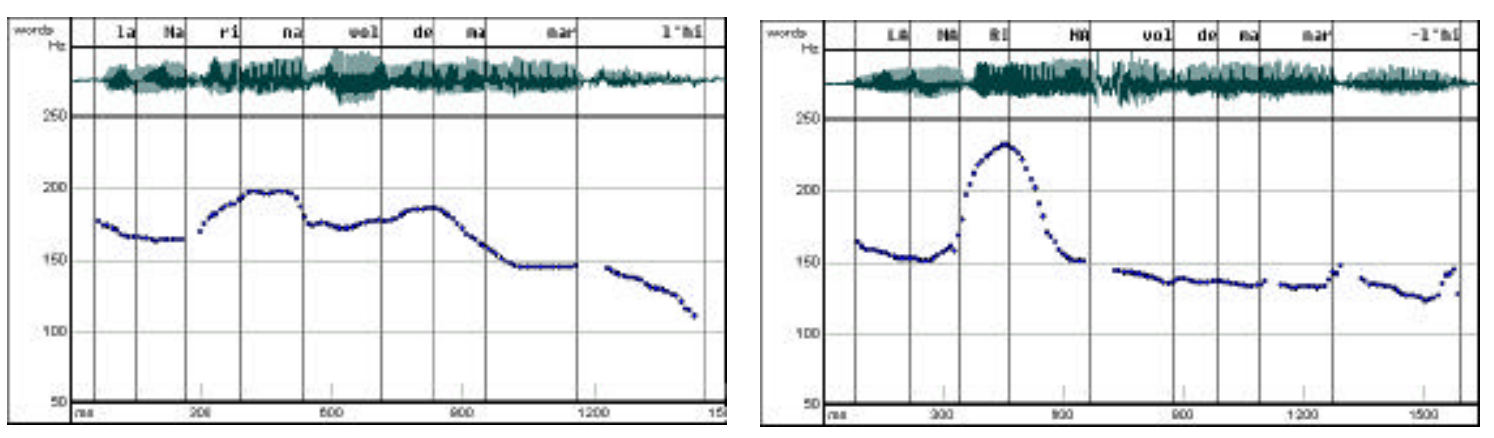

Figure 10. Waveforms and F0 contours of the utterances La Marina vol demaNAR-l'hi 'Marina wants to ask him' (broad focus) vs. La MaRIna vol demanar-l'hi 'MARINA wants to ask him/her' (narrow contrastive focus).

In sum, the data in this section show that a three-way alignment contrast can be found in prenuclear position in Catalan, as follows: (i) a rise with a delayed peak is found in prenuclear accents in statements; (ii) a rise with a peak aligned with the end of the syllable is found in prenuclear accents in imperative sentences; (iii) a posttonic rise is 
found in prenuclear accents in yes-no questions. Thus, leaving aside the question of nucleus location, these contrasts are all active in prenuclear position.

Finally, both Catalan and Spanish can optionally have prenuclear rising accents with $\mathrm{H}$ anchored to the right edge of the prosodic word (Estebas-Vilaplana 2000, 2003; but see Prieto submitted). Recently, some experiments have observed that prenuclear peaks in both Catalan and Spanish strictly align with the right edge of the word (Arranz \& Garrido ms for Spanish and Estebas-Vilaplana 2000, 2003 for Catalan). In her thesis, Estebas-Vilaplana analyses prenuclear rises as instances of a low pitch accent associated to the accented syllable $\left(\mathrm{L}^{*}\right)$ plus a word edge tone $(\mathrm{H})$ anchored at the end of the word. Tonal association to word edges can be used in different Romance languages as optional cues to initial word demarcation and emphasis (see Welby 2003, 2004 for French, Hualde 2003a for Occitan, and Vigário \& Frota 2004 for Northern European Portuguese).

We thus propose that rising accents in Catalan can take the patterns illustrated in Figure 11: (a) a rise with a delayed peak; (b) a rise with a peak aligned with the end of the syllable; (c) a rise with a peak aligned with the end of the word; (d) a posttonic rise. We have taken the view that $\mathrm{L}+\mathrm{H}^{*}$ may be realized both as configurations (a), (b), or (c) in the figure —and that configurations (a) and (c) are allophonic. This interpretation is in accordance with the fact that the $\mathrm{H}$ coming from a bitonal accent can be placed at different metrical locations, namely, the end of the mora, the syllable, or the prosodic word. In short, the Catalan contrasts uncover a case where a different alignment to metrical anchors can be contrastive (or allophonic) within a language. ${ }^{8}$ 

(a) rise with
(b) rise with
(c) rise with
(d) posttonic rise

delayed peak

peak aligned to

peak aligned to

end of $\sigma$

end of $\omega$
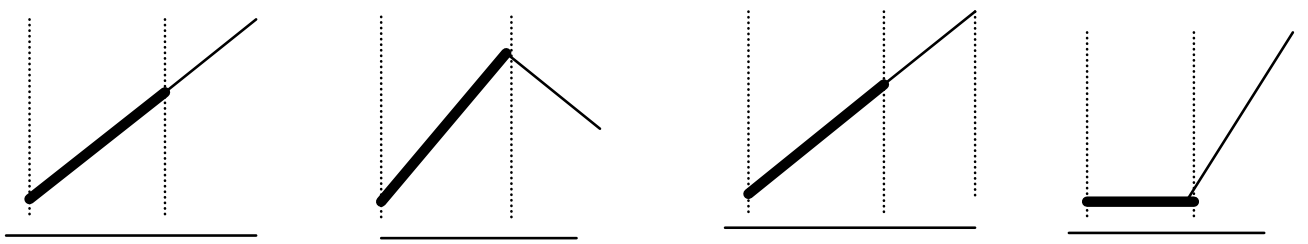

Figure 11. Schematic representation of the rising LH pitch accents in Catalan.

What could be an adequate phonological analysis for the alignment contrasts found in Catalan? The standard AM analysis defended for Spanish prenuclear accents would not capture the observed contrasts in Catalan. Remember that in Spanish (similarly to Neapolitan Italian, see $\S 4$ below) the two-way alignment contrast is transcribed as $\mathrm{L}^{*}+\mathrm{H}$ (rises with late $\mathrm{H}$ alignment) and $\mathrm{L}+\mathrm{H}^{*}$ (rises with early $\mathrm{H}$ alignment) (Face 2001a, Beckman et al. 2002, Hualde 2002). The problem is that the use of $\mathrm{L}^{*}+\mathrm{H}$ to express a delayed peak means that this label is not available anymore to transcribe a posttonic rise. The Catalan data thus prompts us to question the validity of a timing opposition that is exclusively binary $\left(\mathrm{L}^{*}+\mathrm{H}\right.$ vs. $\mathrm{H}+\mathrm{L}^{*} ; \mathrm{H}^{*}+\mathrm{L}$ vs. $\left.\mathrm{L}+\mathrm{H}^{*}\right)$. A possible option that could be entertained to solve this representational puzzle would be to resort to Ladd's (1983, 1996, p. 55) suggestion about using a phonological feature such as [delayed peak] or [+dp] as an attribute of accents, much in the same way the attribute [downstepped] and [upstepped] are used. As Ladd (1994) points out, "accents, in addition to being high or low, can be downstepped or non-downstepped, delayed or non-delayed, raised or non-raised." 
The Catalan three-way pitch accent contrast could be represented as follows: (a) $\mathrm{L}+\mathrm{H}^{*}[+\mathrm{dp}]$ : a rise with a delayed peak; (b) $\mathrm{L}+\mathrm{H}^{*}$ : a rise with an non-delayed peak; and (c) $\mathrm{L}^{*}+\mathrm{H}$ : a posttonic rise. Yet, this analysis would have difficulties accounting for cases where the peak is aligned with the end of the word, as the feature [-delayed peak] assumes that the anchor point is the end of the syllable. Even though Estebas-Vilaplana considers that $\mathrm{H}$ is a word-edge tone that is not part of the pitch accent, here we take the view that the $\mathrm{H}$ comes from the bitonal accent and that this $\mathrm{H}$ tone can be placed at different metrical locations. Within our proposal, the word-edge $\mathrm{H}$ tone of the pitch accent $\mathrm{L} * \mathrm{H}$ - could be reinterpreted as a starred tone $\mathrm{H}^{*}$ with a secondary association to the right edge of the prosodic word $\left.\mathrm{L}+\mathrm{H}^{*}\right] \omega$. We believe that this reanalysis has several advantages over Estebas-Vilaplana's. First, the notation proposed accounts for two related facts: (a) that $\mathrm{H}$ is the part of the pitch accent that is perceived to be more prominent and (b) that the right edge of $\mathrm{H}$ is aligned with the right edge of the prosodic word. Second, it evidences a parallelism between different types of association of tones to metrical edges, be it moras, syllables, or prosodic words. In our view, we can provide a more comprehensive analysis of rising accents in Catalan with a proposal that involves the notion of secondary association.

\section{PRIMARY AND SECONDARY ASSOCIATIONS OF TONES IN PITCH}

\section{ACCENTS}

We start with the AM assumption that phonological representations of pitch accents should distinguish between the autosegmental information (pitch accent shape) and the metrical information (association and alignment information). With respect to the 
metrical information, one of the main claims in the article is that the phonological representation of tones has two complementary ways of encoding tonal alignment:

1. Primary association (or affiliation) will encode a basic association between the whole accent and its tone-bearing unit through the use of the star $*$ notation. In this proposal, starredness in bitonal accents is reserved exclusively to indicate phonological affiliation of a given tone to a given metrically prominent syllable. The star will be assigned on perceptual grounds and thus will not assume a strict relationship between 'phonetic alignment' and 'phonological association'.

2. Secondary association will encode the metrical anchoring site. In some languages, it will be necessary to specify phonological differences in tonal alignment through phonological association/anchoring of tones to prosodic edges (moras, syllables and prosodic words).

Within this view, the surface alignment of tones is obtained through the combination of two sources. We thus propose to extend the notion of secondary association of tones initially proposed by Pierrehumbert \& Beckman (1988). As we will see in this section, we have independent evidence for multiple association from the behavior of phrase and edge accents (Elordieta 1998, Frota 2003, Grice, Ladd \& Arvaniti 2000, Gussenhoven 2000, Gussenhoven \& van der Vliet 1999, Hualde 2003, and Welby 2003, 2004).

Let us now proceed to develop our proposal in two stages. 


\subsection{Primary Associations and Starredness}

As mentioned earlier, the AM approach to intonation encodes tonal alignment in the phonological representation of pitch accents through the use of the star notation. The star notation specifies that the starred tone is the one that associates with the metrically prominent syllable. In bitonal accents, it also makes reference to the relative alignment of tones: in a widely accepted interpretation, the starred tone will be the one that will be aligned phonetically with the accented syllable. In the preceding sections, it was made clear that the use of the star notation cannot solely be based on phonetic alignment between the tone feature and the accented syllable. We believe that Arvaniti, Ladd \& Mennen (2000, p. 130) are essentially correct when saying that "we cannot use phonetic alignment with the stressed syllable as the defining characteristic of starred tones, i.e., of their phonological association."

In our notational proposal, the use of the star diacritic will be reserved to indicate a primary phonological 'association' or 'affiliation' between the tone and its tone-bearing unit. The definition adopted here goes back to a strong version of the original Pierrehumbert proposal that "a strength relationship is defined on the two tones of bitonal accents: and that it is the stronger tone which lines up with the accented syllable" (Pierrehumbert 1980, pp. 76-77). Beckman \& Pierrehumbert (1988, p. 125) also propose that bitonal pitch accents have the following structure, where branches of $\mathrm{T}$ are either $s$ (trong) or $(w)$ eak. The following figure represents the only pitch accent type available in the Japanese tone tier: 


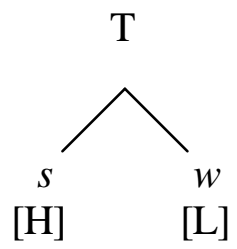

In bitonal accents, the star will be assigned according to perception of tone relationships. The stronger tone $(\mathrm{H}$ or $\mathrm{L})$ will be starred according to perception of the prominent syllable: that is, depending on whether the prominent syllable is heard with a "high tone" or with a "low tone" by native speakers of the language: in the first case the high tone is the main component of the pitch accent, and the syllable can be heard with a high tone; in the second case, the low tone is its main component, and the syllable may be heard with a low tone. ${ }^{9}$ It follows that the two tones in a bitonal accent are in a binary relationship and that only one can be the starred tone. Other prosodic notions such as stress or accent are based on perceptual grounds (as they relate to notions of linguistic prominence that involve a relation between strong and weak) and crucially do not have a strict translation into phonetic features. Thus, while accented syllables are generally signalled by local F0 changes in the vicinity of the stressed syllable, crucially there is no direct and necessary phonetic interpretation of accent: in other words, these notions might be signalled by certain phonetic features, but they are not strictly necessary. Accordingly, as Pierrehumbert originally remarked, "The starred/unstarred relation in pitch accents may be compared to the stressed/unstressed relationship within the metrical foot, an entity which will also play a role in our discussion of text/tune association. (..) The bitonal accents resemble bisyllabic feet in that they consist of two elements ordered in time on which a strength relationship is defined; the starred tone is the stronger one, and the unstarred one is the weaker one." (Pierrehumbert, 1980, pp. 23-25). 
Figure 12 shows the four typological possibilities that arise in bitonal accents with only primary associations together with some typical phonetic realization patterns. The first two pitch accents are perceived as (mainly) high accents and the last two are perceived as (mainly) low accents. In order for a syllable to be perceived as high, the pitch level needs to stay high or rise for a good portion of the accented syllable; conversely, in order for a syllable to be perceived as low the pitch level must stay low or fall for a good portion of the accented syllable. Thus $\mathrm{H}^{*}$ can either align with the beginning or the end of the syllable depending on whether one has some other tonal specification before or after. Similarly, $\mathrm{L}^{*}$ can either align with the beginning or the end of the syllable.

HIGH accents

$\mathrm{L}+\mathrm{H}^{*}$

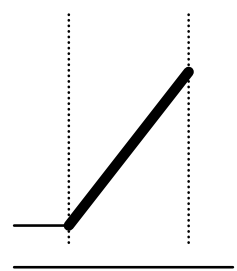

$\mathrm{H}^{*}+\mathrm{L}$

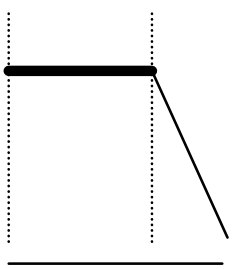

LOW accents

$$
\mathrm{L}^{*}+\mathrm{H}
$$

$\mathrm{H}+\mathrm{L}^{*}$
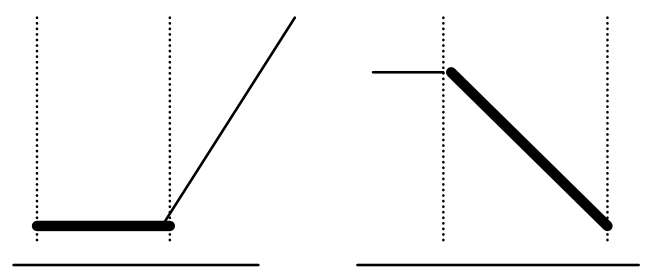

Figure 12. Basic typology of bitonal accent types according to different primary associations of $\mathrm{H}$ or $\mathrm{L}$.

The two graphs in Figure 13 illustrate two examples of contrastive falling accents in Central Catalan, namely, $\mathrm{H}+\mathrm{L}^{*}$ vs. $\mathrm{H}^{*}+\mathrm{L}$-for more examples of timing contrasts with falls see Bruce (1977) for Swedish word accents, Verhoeven (1994) and Caspers (1999) for accent-lending falls in Dutch, and Frota $(2000,2002)$ for the broad/narrow focus distinction in European Portuguese. In Central Catalan, the main difference between a 
given type of polar (or yes-no) question such as Que l'ha llogada? 'Did (s)he rent it?' (left panel) and a wh-question such as Qui l'ha llogada? 'Who rented it?' (right panel) is in the alignment of the falling nuclear accent. While in yes-no questions the falling gesture starts at the beginning of the stressed syllable (which is perceived to have a $\mathrm{H}$ tone) in the wh-question the fall starts toward the end of the stressed syllable (which is perceived to have a $\mathrm{L}$ tone): ${ }^{10}$

$\underline{\text { Yes-no question }}$

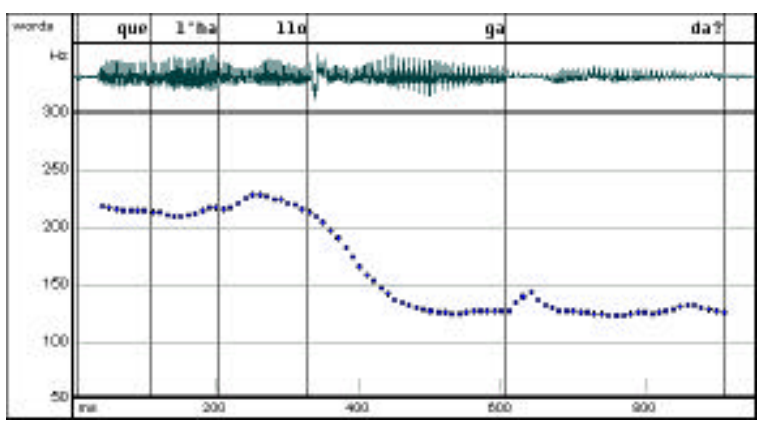

Wh-question

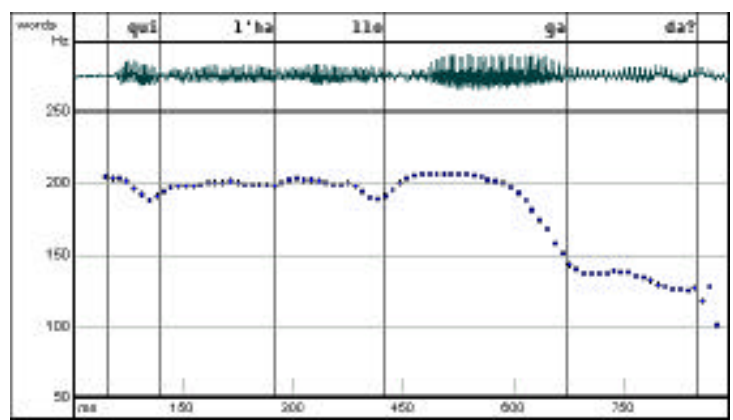

Figure 13. Waveforms and F0 contours of two types of interrogative sentences in Catalan: Que l'ha lloGAda? 'Did (s)he rent it?' (left panel) vs. Qui l'ha llogAda? 'Who rented it?' (right panel).

How will the actual phonetic alignment be obtained in bitonal accents with only primary associations (e.g., bitonal accents in Figure 11)? Following standard autosegmental treatment, the surface alignment pattern will be obtained through the following mapping procedure. First, the pitch accent will be associated through 'central' alignment whereby the alignment property percolates to the head (for a definition of central vs. peripheral alignment, see Pierrehumbert \& Beckman 1988 and Grice 1995). ${ }^{11}$ In the typical case (English), the pitch accent is associated to the metrical foot (English permits at most one pitch accent per metrical foot) and the association is passed down the tree to the head. In their terms, "the accent is a foot-level property that is attracted to the head syllable." 
(Pierrehumbert and Beckman, 1988, pp. 159). Second, as Pierrehumbert \& Beckman (1988, p. 125) state, "the strong tone ( $\mathrm{H}$ in this case) would have priority in establishing the alignment." After that, we propose the following procedure of tone linking. First, we assume that both the left and the right edges of accented syllables are the basic anchor points for target tones in pitch accents. The starred tone will first be aligned to the right periphery of the metrically prominent syllable (cf. Figure 11). The final form of the pitch accent will depend in part on its leading or trailing tone specifications: leading tones will be linked to the left edge of the syllable; conversely, trailing tones will be located in the right periphery of the syllable, following the view that trailing tones are found at a given time interval after the starred tone (Pierrehumbert 1980, Grice 1995; for an argument against such view, see Arvaniti, Ladd \& Mennen 1998). In the case of bitonal accents with trailing tones, the left edge of the syllable is left without tonal specification: thus the starred tone will have to be doubly linked both at the beginning and at the end of the syllable. This double link follows from the perceptual restriction that in order for a syllable to be perceived as high or low in this context this feature has to span over a good portion of the syllable. Finally, the rest of the contour will be obtained through phonetic interpolation between target tones. Eventually this model will need to incorporate a phonetic implementation module that takes into account the fact that different languages might implement the same pitch accent in different ways.

As we will see, the Catalan (and Italian) data represent evidence that pitch accents that are perceived as essentially high $\left(\mathrm{H}^{*}\right)$ can have three different anchoring points for the $\mathrm{H}$ target, namely, end of the mora, end of the syllable, and end of the word. In these cases, the phonological representation of pitch accents needs to specify the anchor site, depending on the constrastive possibilities alignment performs in the language. 


\subsection{Secondary Association to Metrical Edges}

The original proposal for double association of edge tones was part of Pierrehumbert \& Beckman's (1988) analysis of the Japanese intonational system. In their book, Pierrehumbert \& Beckman acknowledge that phrasal tones may acquire additional links (what they call "secondary associations") to a specific tone-bearing unit or to another boundary. For example, the Japanese utterance-initial L usually seeks a secondary attachment to the first mora of the utterance. Similarly, the phrasal $H$ which is associated underlyingly with the left edge of the accentual phrase is realized on the second mora. The concept of secondary association is understood as the simultaneous association of a tone to a higher-level constituent, like the intonation phrase, and a lower-level constituent, like the mora. This concept has gained a broad acceptance and has recently been applied to different languages to explain the behavior of phrase accents and edge tones (see Elordieta 1998 for Lekeitio Basque; Frota 2003 for phrasal H tones in European Portuguese; Grice, 1995, p. 185 for Palermo Italian; Grice, Ladd \& Arvaniti, 2000 for Eastern European languages, Gussenhoven \& van der Vliet, 1999 and Gussenhoven, 2000 for tonal dialects of Dutch, Jun \& Fougeron, 2000, Welby, 2003 for French, and Hualde, 2003a for Occitan). They all acknowledge that phrasal tones may acquire additional links ("secondary associations") to a specific site in the metrical tree. In what follows we summarize the types of edge-tone secondary attachments that have been found in the literature, namely, with metrically prominent syllables, with moras, and with word-edges: 
(1) Secondary alignment of edge tones to stressed syllables:

Elordieta (1998) showed that the behavior of the $\mathrm{H}$ phrasal tone in Lekeitio Basque was similar to the behavior of phrasal tones in Japanese: this tone phonologically belongs to the accentual phrase but it is secondarily associated to the second syllable of the accentual phrase. On the other hand, Grice (1995) shows that intermediate phrase boundary tones in Palermo Italian seek a secondary association with a stressed syllable. Similarly, Grice, Ladd, \& Arvaniti (2000) demonstrate that phrase accents in Eastern European languages like Romanian and Greek may exhibit an additional tendency to look for a metrically prominent syllable for its association. Finally, D'Imperio (2001) found that the final fall of Neapolitan narrow focus constituents of questions (which is a HL phrase accent) is usually anchored to the last stressed syllable of such constituents, thus either merging with the pitch accent $\mathrm{H}$ tone or becoming itself a pitch accent proper (in this case, the notation employed is $\mathrm{H}(*) \mathrm{L}-$, see also Grice, Ladd \& Arvaniti 2000 and Grice et al., 2005b).

(2) Secondary alignment of edge tones to moras:

For Japanese, Pierrehumbert \& Beckman (1988, p. 178) report on four types of edge tones that are commonly aligned to moras, as follows: "The phrasal $\mathrm{H}$ is regularly associated to the first or second sonorant mora of the accentual phrase; and the accentual-phrase final and utterance-initial L\% boundary tones, both of which are associated to the first mora of the following accentual phrase only if this mora has no tone." Similarly, Gussenhoven \& van der Vliet, 1999 and Gussenhoven (2000) show that, in fact, not just boundary tones but also lexical tones will acquire this 
secondary association if a stressed mora is available. Gussenhoven (2000) posits a boundary tone in the Dutch dialect of Roermond which has two targets: a primary association with the end of the intonational phrase and a secondary moraic association.

\section{(3) Secondary alignment of edge tones to word edges:}

French intonation is characterized by an obligatory tonal rise on the hst syllable of a phrase (a non-utterance final phrase) and an optional early rise occuring somewhere before the late rise. In Jun \& Fougeron's (2000) analysis, the early rise and the late rise together form the accentual phrase (AP), which has the underlying structure /LHiLH*/. The early rise (LHi) is a phrase accent with an association to the left edge of the AP. The late rise is a $\mathrm{LH}^{*}$ pitch accent whose $\mathrm{H}^{*}$ tone is associated to the last full syllable of the AP. Welby (2003, 2004) strongly supports the hypothesis that the $\mathrm{L}$ of the early rise is an edge tone (part of a compound edge tone) with a double association to the left edge of the first content word and to the left edge of the prosodic phrase. In a similar vein, Occitan has been reported to have secondary accents at the beginning of words or phrases (see Hualde 2003b): in his analysis, he employs the same notation Jun \& Fougeron (2000) used for French, namely, (L)+Hi. Similarly, Frota (2003) proposes that the left periphery of statements in European Portuguese can be indicated through an $\mathrm{H}$ phrasal tone that has a peripheral association to the left edge of the intonational phrase and a secondary association of the first prosodic word. 
Figure 14 shows the schematic representation of the primary and secondary associations of a phrasal $\mathrm{H}$ within the accentual phrase in Japanese (Pierrehumbert \& Beckman, 1988, p. 129). The solid line indicates primary association to the accentual phrase $\alpha$ and the dashed line secondary association to the second sonorant mora $\mu$ within the accentual phrase.

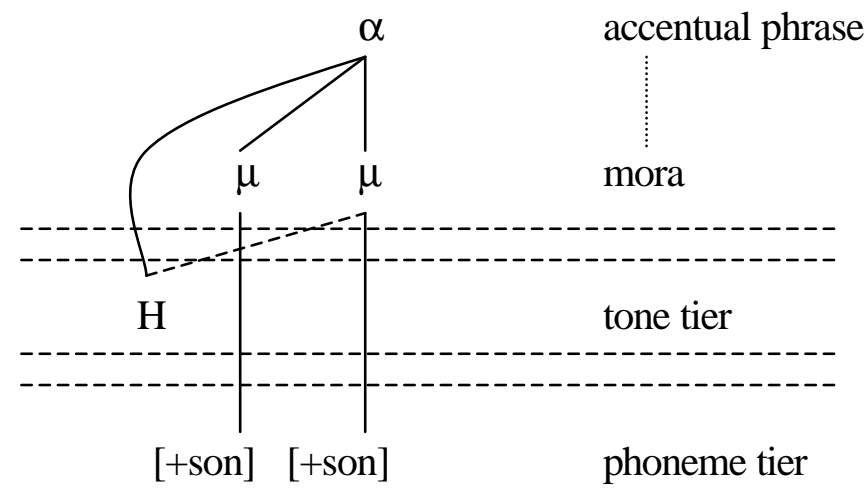

Figure 14. Autosegmental representation of the primary association of the $H$ phrasal tone to the accentual phrase $\alpha$ and of the secondary association of this $H$ tone to the second mora $\mu$ in Japanese (after Pierrehumbert \& Beckman, 1988, p. 129).

In this section, we propose to extend the notion of "secondary association" originally proposed by Pierrehumbert \& Beckman (1988). The claim is that not only phrase edges can seek edges of metrical units as anchor points, but also tones in pitch accents can do so. That is, specific $\mathrm{L}$ or $\mathrm{H}$ tones within pitch accents can be secondarily attached to edges of metrical constituents, be it at left or right periphery of moras $([\mu, \mu])$, syllables $([\sigma, \sigma])$, and prosodic words $([\omega, \omega])$. Thus secondary association is especially appropriate to express the details of the independent alignment of $\mathrm{H}$ in the autosegmental representation: for the Catalan case, we might say that the $H$ is secondarily associated with the right edge of the syllable or with the right edge of the 
word. In this way, secondary associations will play a primary role in determining the phonetic timing of tones by overriding the standard mapping procedure applied to pitch accents with only primary associations of tones (see §3.1). Further motivation for having a more refined metrical mechanism within the AM model is the recent proposal by Beckman (2004) to recast pitch accent typology to refer to structure where tones are anchored. As she notes, "languages differ on whether they have a variety of pitch accent shapes (...), but we also find that these accent shapes can be anchored to different metrical structures depending on the language."

The addition of this complementary alignment mechanism allows for a more complete inventory of pitch accents that can account in a more transparent way for the non-binary oppositions in timing reported for Central Catalan. Let us now remember the contrastive possibilities of alignment found in this language. The schematic diagrams in Figure 15 illustrate the three-way phonological contrast reported for Catalan plus the pitch accent $\left.\mathrm{L}+\mathrm{H}^{*}\right] \omega$ (which was classified as an allophonic variant of the rise with a delayed peak, schematized here in (c)).
(a) rise with
(b) rise with
(c) rise with
(d) posttonic rise

delayed peak

peak aligned to

peak aligned to

end of $\sigma$

end of $\omega$
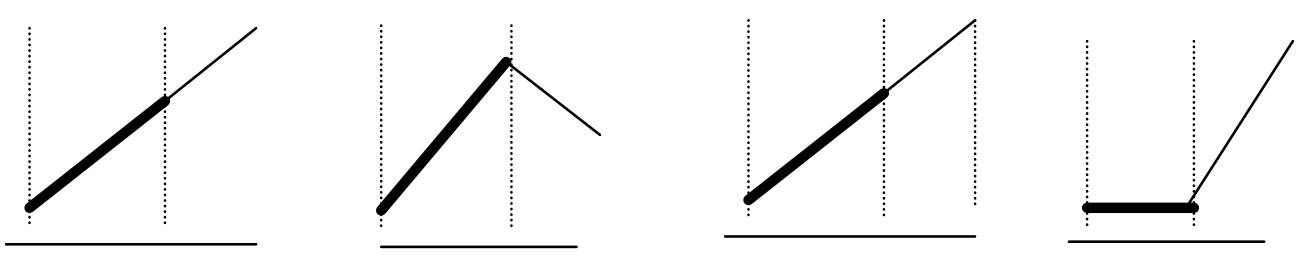

Figure 15. Schematic representation of the contrasts in alignment in rising LH pitch accents in Catalan. 
Figure 16 provides the autosegmental representation of primary and secondary associations in rising LH pitch accents in Catalan. First, the use of the star indicates the primary phonological association between the tone and the metrically prominent syllable: in this sense, there is a main contrast between the high accents $\mathrm{H}^{*}$ (first three pitch accents, represented as $\mathrm{L}+\mathrm{H}^{*}$ ) and the low accent $\mathrm{L}^{*}$ (last accent, represented as $\left.\mathrm{L}^{*}+\mathrm{H}\right)$. Following Pierrehumbert \& Beckman (1988), the pitch accent is associated to the foot and percolates down to the tone-bearing unit, namely, the metrically strong syllable within the foot. Second, what distinguishes between the three high accents $\mathrm{L}+\mathrm{H}^{*}$ is the specification of the anchoring point for $\mathrm{H}$ (i.e., its secondary association), namely, the right periphery of the syllable in (b) or the prosodic word in (c). As in Figure 14, the solid lines represent primary associations that percolate down the prosodic tree and the dashed lines represent a secondary link with the prosodic tree.
(a) rise with
(b) rise with peak aligned to
(c) rise with
(d) posttonic rise delayed peak end of $\sigma$ peak aligned to end of $\omega$
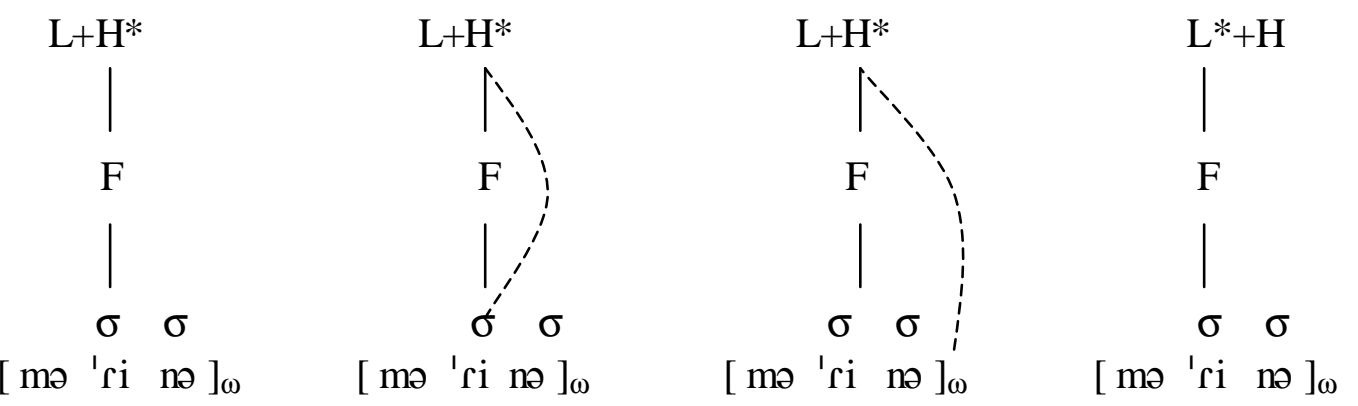

Figure 16. Autosegmental representation of the primary associations of the whole accent (solid line) and the secondary associations of the individual tone $\mathrm{H}$ to the rightedge of the syllable and to the right-edge of the word (dashed lines) in rising LH pitch accents in Catalan $(\omega=$ prosodic word, $F=$ foot, $\sigma=$ syllable $)$. 
The tonal representations above crucially capture the similarities between the rising pitch accents ((i) all of them have the same LH accent shape; (ii) the first three are perceived as high $\mathrm{H}^{*}$ ) and their main differences, namely, their anchoring point to a different metrical edge. Moreover, this representation enables us to characterize the distinction between obligatory alignment at an edge (case (b) and (c) above) and more freely aligned targets (case (a) and (d)). ${ }^{12}$

The Catalan data thus provides crucial evidence for syllable-edge and word-edge secondary tonal associations. The diacritics specifying the metrical anchors in the phonological component could be represented as follows:

(i) rise with delayed peak, $\mathrm{L}+\mathrm{H}^{*}$;

(ii) rise with peak associated to the edge of the syllable, $\left.\mathrm{L}+\mathrm{H}^{*}\right] \sigma$;

(iii) rise with peak associated to the edge of the prosodic word, $\left.\mathrm{L}+\mathrm{H}^{*}\right] \omega$;

(iv) posttonic rise, $\mathrm{L}^{*}+\mathrm{H}$.

Clearly, then, like in the case of edge tones, a distinction is drawn between pitch accents with and without secondary associations. The contrastive possibilities of alignment within the language in question will in fact determine the secondary association properties that should be incorporated in the phonological representation. In this sense, the case of Serbian spoken in Belgrade offers an interesting 4-way contrast in peak alignment (Hualde \& Smiljanic 2000, Smiljanic 2002, forthcoming). This language has a lexical contrast between two types of accents, namely, a rising accent with a nondelayed peak and with a delayed peak (that is generally placed in the posttonic). Moreover, when these accents are in a narrow focus situation, the peaks of the two 
accents shift leftwards and are placed towards the middle of the stressed syllable. ${ }^{13}$ More studies are needed to further explore the contrastive possibilities of alignment in different languages.

It is important to emphasize that secondary associations of tones are used in languages that exploit a variety of pitch accent contrasts. Secondary associations are not used here to describe differences in details of alignment found across languages (see Atterer \& Ladd 2004) and even within the same language (see Prieto \& Torreira 2004). We basically agree with Ladd (2004:127) that "using secondary association to represent the phonetic detail of alignment would lead to a rapid proliferation of distinct phonological representations for subtly different variations of phonetic detail between languages or between language varieties." For example, as Ladd contends, "to express the differences among English, Northern German, and Southern German demonstrated by Atterer \& Ladd (2004), we would have to associate the initial L tone of the rise with the left edge of the accented syllable (English), the left edge of the accented syllable nucleus (Southern German), or the onset of the accented syllable (Northern German), and posit similar differences for the association of the $\mathrm{H}$ tone." We believe that the specific points of alignment for each language need to be dealt with in a quantitative manner in the mapping mechanisms.

The following two sections will discuss the application of our proposal to the contrastive alignment possibilities found in Neapolitan Italian and Pisa Italian pitch accents. Both systems provide crucial evidence that small differences in $\mathrm{H}$ alignment in pitch accents are of great importance in the perception of linguistic contrast and are thus exploited in the phonological component. We argue that these phonological contrasts 
can be represented in a straightforward way by mora-edge vs. syllable-edge secondary tonal associations.

\section{NEAPOLITAN ITALIAN}

Similar to the varieties spoken in Palermo and Bari (Grice et al., 2005), the variety of Italian spoken in Naples employs a rising nuclear accent followed by a falling phrase accent in order to signal yes/no questions (D'Imperio, 2002a). This pitch accent was first labelled as a L+H* accent (D'Imperio, 1995; D'Imperio and House, 1997), but then relabelled as a $\mathrm{L}^{*}+\mathrm{H}$ on the basis of the reanalysis of the nuclear pitch accent of narrow focus statements (cf. D'Imperio, 1999, 2003). The shape of both yes/no question and narrow focus statement contours is indeed quite similar, since a rise-fall pattern characterized by a salient peak marks the section of the contour from the nuclear syllable up to the end of the focused constituent, as can be seen in Figure $17 .{ }^{14}$ Though both nuclear accents in these contours can been analyzed as bitonal (LH), rising pitch accents, the temporal alignment of the tonal targets appears to be systematically different, both in perception and production.
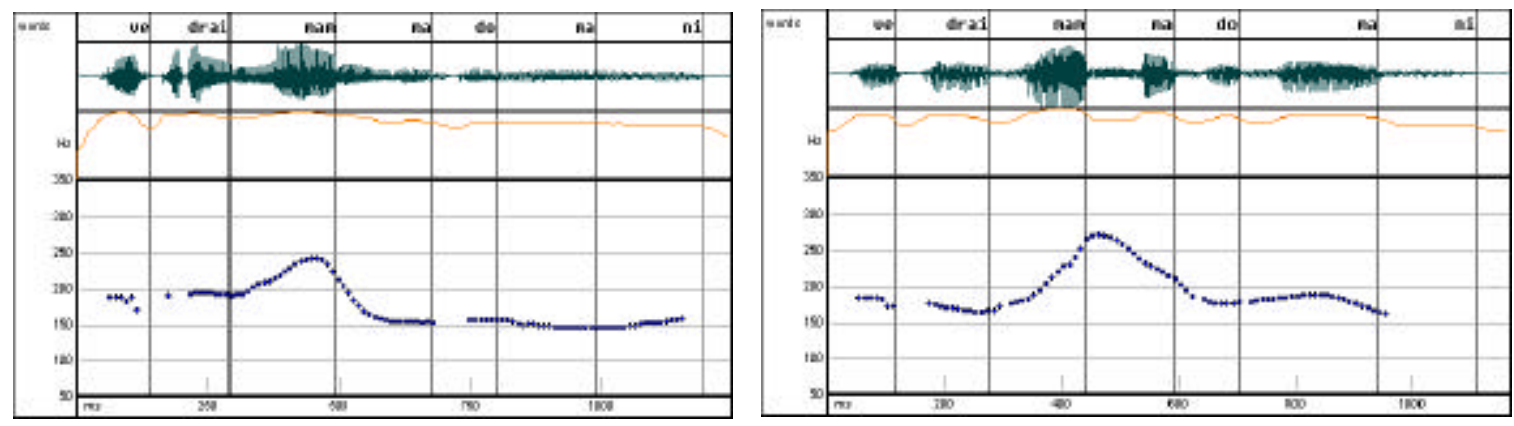

Figure 17. Waveform and F0 tracks of the narrow focus statement Vedrai MAMma domani 'You will see MOM tomorrow' (left panel) and of the narrow focus yes/no question Vedrai MAMma domani? 'Will you see MOM tomorrow?' (right panel). 
The first striking fact is that peak alignment is different and is at the same time a crucial factor in determining whether an utterance is perceived as a yes/no question or a narrow focus statement (D'Imperio and House, 1997). ${ }^{15}$ Question peaks are in fact later than statement peaks, all else being equal. However, when observing the entire rise-fall contours, it appears that all three targets (LHL) of the question contour are indeed timed later relative to the sressed syllable (D'Imperio, 2000). That is, not only is the question peak later, but also the starred $\mathrm{L}$ tone of the $\mathrm{L}^{*}+\mathrm{H}$ accent seems to occur later than the leading $\mathrm{L}$ of the statement $\mathrm{L}+\mathrm{H}^{*}$. Specifically, while the $\mathrm{L}$ target of $\mathrm{L}+\mathrm{H}^{*}$ tends to occur right at the onset of the stressed syllable (in a manner similar to the $\mathrm{L}$ tones of rising accents in many other languages, see $\S 1$ above), the $\mathrm{L}$ of the question $\mathrm{L}^{*}+\mathrm{H}$ rise tends to occur within the first half of the stressed vowel, as Figure 18 shows. Also, while the $\mathrm{L}+\mathrm{H}^{*}$ peak always occurs within the boundaries of the stressed vowel, the $\mathrm{L}^{*}+\mathrm{H}$ peak occurs either late within this vowel (when the stressed syllable is open), or even beyond the boundaries of the stressed vowel and as late as the sonorant coda of closed, stressed syllables. In other words, the hypothesis of D'Imperio (2000) that the alignment of the L1, H and L2 targets would be affected by the question vs. statement contrast was confirmed, thus partly replicating the findings of D'Imperio (1995, 1996, 1999). 


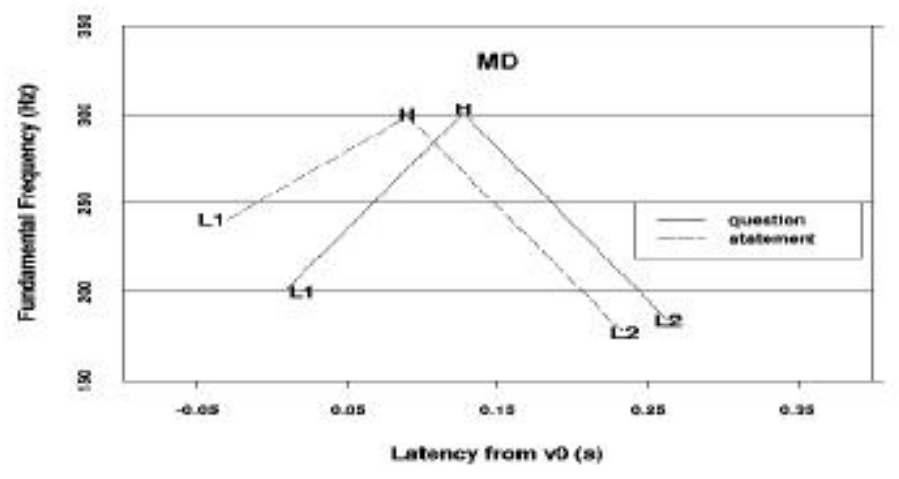

Figure 18. F0 values and latency from v0 (vowel onset) for L1, H and L2 targets for a speaker of Neapolitan Italian (D'Imperio, 2000, p. 100). Dashed line: statement utterance; solid line: question utterance.

Note that the analysis of the narrow focus pitch accent of statements as a rising $\mathrm{L}+\mathrm{H}^{*}$, proposed in D'Imperio (1999, 2003), was instrumental in deciding the starredness status of the $\mathrm{L}$ in the $\mathrm{L}^{*}+\mathrm{H}$ of questions. In fact, from alignment facts alone, it is not immediately clear whether the $\mathrm{L}$ tone, the $\mathrm{H}$ tone or both are associated to the stressed syllable, since both the low and the high targets are realized within the stressed syllable boundaries, when the accent is nuclear and placed on a one-word focused constituent. However, since the narrow focus statement pitch accent must have a LH structure and not a HL one (see D'Imperio, 2003 for arguments in favor of this analysis), we are faced with the existence of two contrasting $\mathrm{LH}$ rising accents where both $\mathrm{L}$ and $\mathrm{H}$ are realized within the boundaries of the stressed syllable, hence are potentially associated/starred tones.

It then follows that the use of a contrastive notation is desirable and even necessary. Nevertheless, the issue at stake here is not merely a notational one, instead it is to decide whether the exact alignment properties of the starred tone within these LH 
accents are a consequence of some non-automatic mechanism encoded in the prosodic representation. It is in this respect that the analysis of Neapolitan Italian offers support to the secondary association proposal which is central to this paper. The existence of a secondary association mechanism in Italian appears to find further support in the behavior of the HL- phrase accent, which seeks secondary association to the last stressed syllable of the focus constituent (D'Imperio, 2000).

One of the conclusions of D'Imperio (2000) was that the anchoring point for the alignment of the $\mathrm{LH}$ rise was located at the left edge and not the right edge of the stressed syllable. In fact, the hypothesis that syllable structure (i.e., open/closed contrast) would affect target alignment relative to the left edge of the syllable was not confirmed, while a difference was found when alignment was measured relative to the right edge of the syllable. Moreover, if peaks were timed to occur relative to the right edge of the stressed syllable, a very complex situation would arise. Namely, the alignment of $\mathrm{H}$ peaks in statement pitch accents associated to a closed syllable can be virtually undistinguishable from the peak alignment of question pitch accents associated to an open syllable (cf. D'Imperio 2002b). In fact, in both cases the accent peak is located very close to the offset of the stressed vowel.

In addition to the results of the production experiment, the results of some perception experiments (D'Imperio and House, 1997; D'Imperio, 2000) show that for a $\mathrm{L}^{*}+\mathrm{H}$ to be identified as such, the "perceived" target for the rise must be late, so late that if the pitch peak has a plateau shape its perceived target will be "pulled" towards the plateau offset. This finding has lead D'Imperio (2000) to propose that the starred tone within bitonal pitch accents of Neapolitan Italian is aligned with the first mora of the stressed syllable, 
which is plausibly the most perceptually salient mora within the syllable itself. Note that independent evidence for mora structure in Italian has also been employed to explain penultimate stressed vowel lengthening as a result of stress and foot structure constraints (D'Imperio and Rosenthall, 1999).

Our proposal is that there is a secondary association between the starred tone and the first mora of the stressed syllable (see (b) in Figure 19). Since both targets, L and H, within both LH rises appear to be anchored in specific ways to the prominent constituent (the stressed syllable, which is the head of the foot and of the intermediate phrase), we must postulate that the LH of questions and of statements is globally associated to the stressed syllable ${ }^{16}$. Hence, for the Neapolitan $\mathrm{L}+\mathrm{H}^{*}$, the starred $\mathrm{H}$ is secondarily associated with the first mora of the stressed syllable, which results in an alignment towards its right edge (i.e., around the middle of the stressed syllable nucleus); analogously, the $\mathrm{L}^{*}$ of the question $\mathrm{L}^{*}+\mathrm{H}$ accent is associated with the same mora (see (c) in Figure 19) and aligned not later than its right edge. This would be plausible with a perceptually-based theory proposing that listeners attend to a globally high level F0 within the first mora in order to identify the $\mathrm{L}+\mathrm{H}^{*}$ of statements, and a low level or simply absence of a high level within the same location in order to identify the $\mathrm{L}^{*}+\mathrm{H}$ of questions. A similar view of perceived target processing was proposed in D'Imperio (2000). 

(a) rise with
(b) rise with
(c) rise with
delayed peak
$\mathrm{H}$ peak aligned to
$\mathrm{L}$ aligned to
first mora
first mora
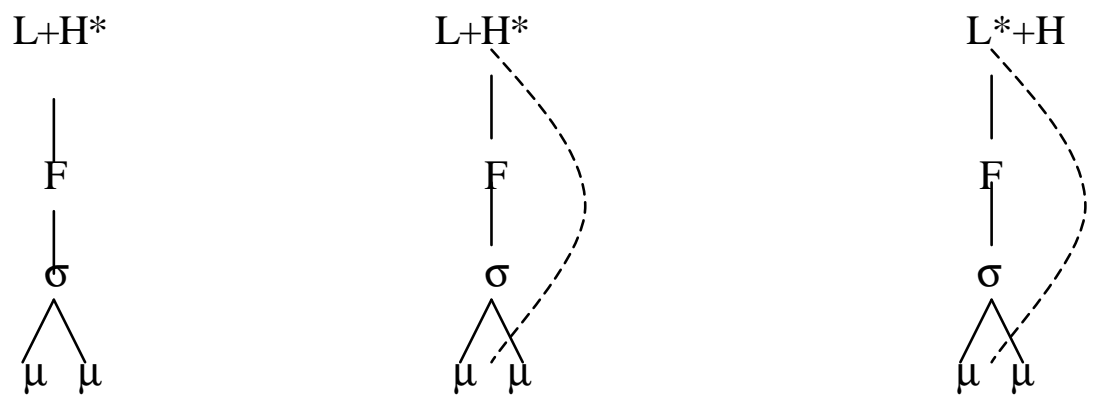
$[\underline{\operatorname{mamma}}]_{\omega}$
$[\underline{\text { mamma }}]_{\omega}$
$[\underline{\text { mamma }}]_{\omega}$

Figure 19. Autosegmental representation of the primary associations of the whole accent (solid lines) and the secondary associations of the starred tone $\left(\mathrm{H}\right.$ for $\mathrm{L}+\mathrm{H}^{*}$ and $\mathrm{L}$ for $\mathrm{L}^{*}+\mathrm{H}$ ) to the first mora of the stressed syllable (dashed lines) in rising $\mathrm{LH}$ pitch accents in Neapolitan ( $\omega=$ prosodic word, $F=$ foot, $\sigma=$ syllable, $\mu=$ mora $)$.

Though at first acoustic evidence seemed to suggest that the $\mathrm{H}$ target of $\mathrm{L}^{*}+\mathrm{H}$ would be aligned with the right edge of the stressed syllable, or with its second mora, informal investigation of monomoraic penultimate syllables show that the $\mathrm{H}$ target is not aligned with a specific prosodic constituent. The secondary association analysis would then correctly account for the fact that in stressed closed syllables (which are bimoraic in that a second mora is linked to the sonorant coda) the F0 peak for $\mathrm{L}^{*}+\mathrm{H}$ occurs beyond the boundaries of the stressed vowel, which D'Imperio (2000) proposes serves the purpose of allowing/facilitating the listener's task in recovering the strong/starred $\mathrm{L}$ tone within the monomoraic vowel. Finally, according to this view, we can reanalyze the prenuclear $\mathrm{H}^{*}$ accent with delayed peak, as an instance of a $\mathrm{L}+\mathrm{H}^{*}$ accent with no secondary 
association, much like the rise with delayed peak of Catalan. In fact, evidence for the existence of an actual $\mathrm{L}$ target has been recently found in a production experiment where pitch range was explicitely manipulated (Gili Fivela \& D'Imperio, 2004).

\section{Pisa Italian}

The variety of Italian spoken in Pisa (Tuscany) shows two pitch accents characterized by a high tone associated to the accented syllable, and a rise to the peak which starts at the onset of the syllable. Yet, only one of them shows an early peak and a low trailing tone. ${ }^{17}$ The two graphs in Figure 20 show the waveform and F0 track of parts of two productions of the sentence La pronuncia di LAvaglielo non (la) ricordo mai 'The pronunciation of 'wash it for him', I never remember (it)' ${ }^{18}$ The graph on the left corresponds to a broad focus interpretation, while the graph on the right shows a narrow (contrastive) interpretation of the left dislocated constituent, representing a syntactically focused phrase. Notice that in both pitch patterns the start of the rise aligns with the beginning of the accented syllable, but while in the narrow focus pitch accent the peak is reached in the first half of the vowel, in the broad focus pitch accent it is reached by the end of the open syllable. Both peaks are then followed by a fall, which is steeper in the pitch pattern shown in the right panel of Figure 20.
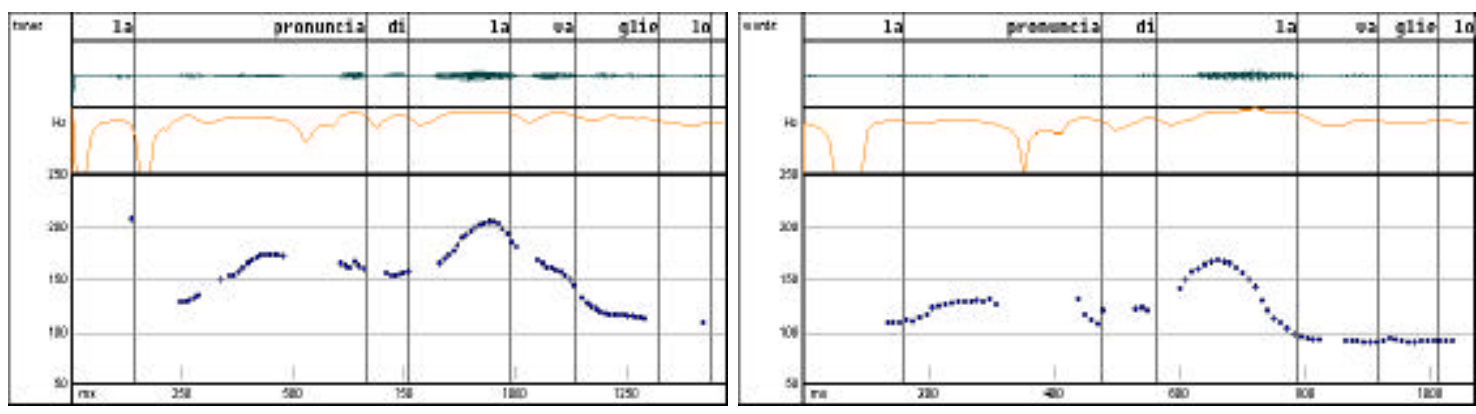
Figure 20. Waveform and F0 track of of the first part of the utterance La pronuncia di

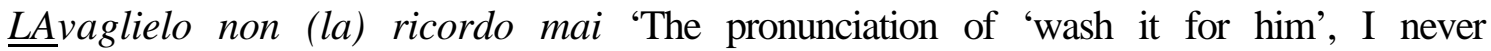
remember (it)' in broad focus (left) and in narrow-contrastive focus (right).

The two patterns are functionally different and formally distinct. The early peak pitch accent (see Figure 20, right) expresses narrow focus with a contrastive interpretation, and it may also be used by speakers to ask for confirmation or may convey incredulity (Gili Fivela, 2004). Figure 21 (left) shows the waveform and F0 track of the utterance Ma sono sempre sulla barca io 'but I am still on the boat' expressing contrastive focus. In Map-Task dialogues ${ }^{19}$, the pitch pattern is interpreted as a confirmation-seeking question when uttered by instruction followers, apparently because they explicitly lack information in comparison to instruction givers (on the contrary, instruction givers may ask for confirmation by realizing the same pitch accent followed by different edge tones, i.e. a low phrase accent and a high boundary tone). The same phonological analysis is reserved for the pattern conveying incredulity/surprise, i.e. realized with disbelieving intonation in Map-Task object moves (Grice \& Savino, 1997). In the latter case, though, a high left boundary tone or a later alignment within the nuclear syllable and/or a greater pitch excursion may be found - see Figure 21, right.
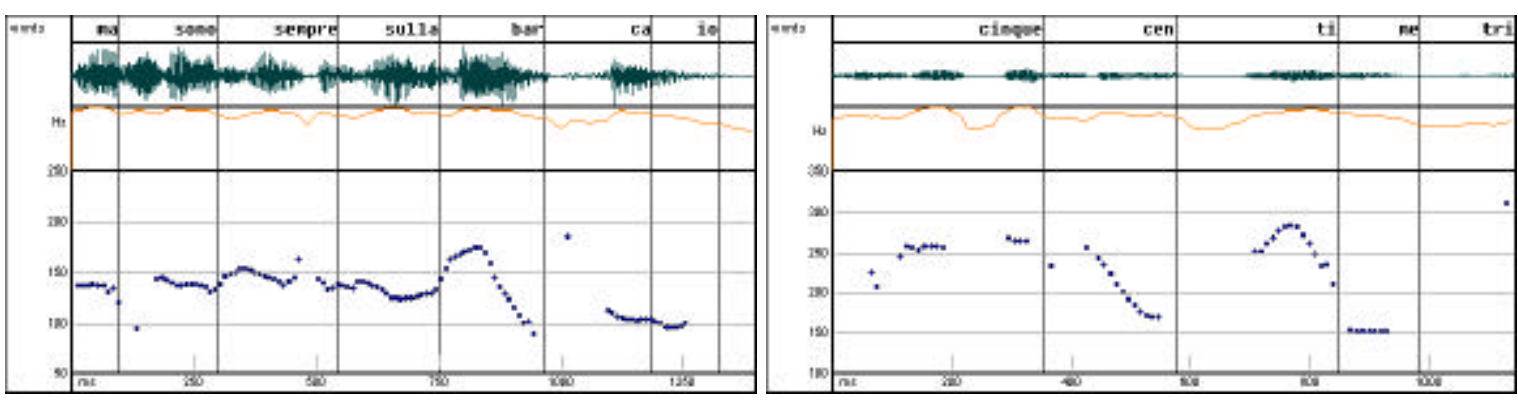

Figure 21. Waveform and F0 track of of the utterance Ma sono sempre sulla BARca io 'But I am still on the boat' (left panel) interpreted as a confirmation seeking question, 
and of the utterance Cinque cenTImetri?! 'Five centimeters?!' (right panel) expressing incredulity/surprise.

By contrast, the later-peak pitch accent is found in prenuclear position in declaratives, although it may also be found in intermediate phrase-final position (see Figure 20, left) or as a nuclear pitch accent in patterns similar to continuation rises (see Figure 22, left). It may also represent the nuclear pitch accent in elliptic questions (see Figure 22, right), in some confirmation seeking questions realized with a low illocutionary force, and in questions suggesting a number of alternatives. The pitch accent may also be used to express narrow focus, but when a contrastive interpretation is at issue, it appears to be related to a weaker illocutionary force and/or to the presence of a syntagmatic contrast rather than a paradigmatic one (for the latter observations, see also Gili Fivela, 1999). As is shown in the graphs, the peak is reached near the end of the nuclear syllable.

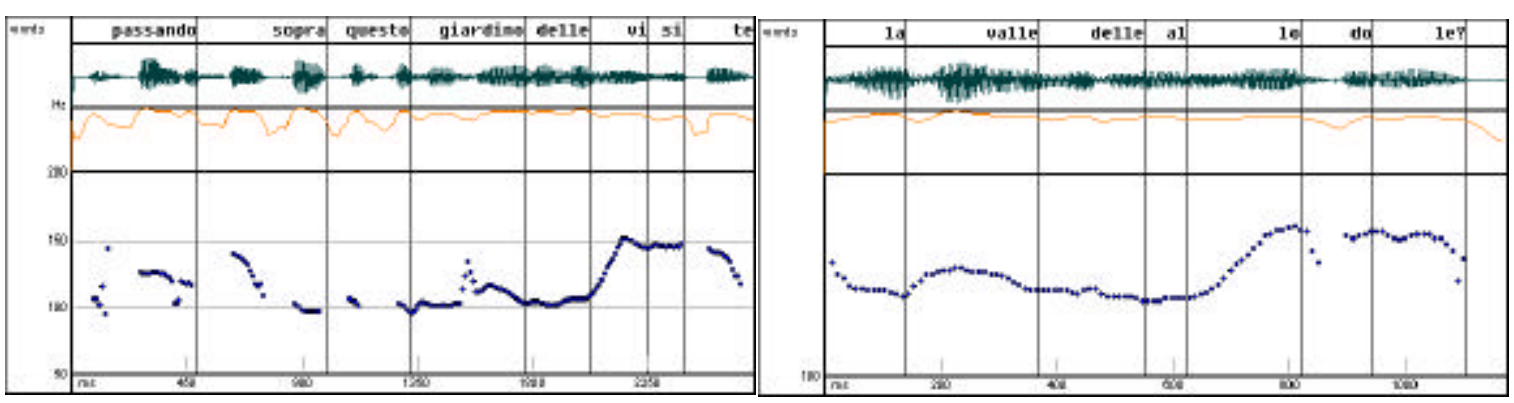

Figure 22. Waveform and F0 track of the utterance Passando sopra questo giardino delle VIsite 'Passing above the visitor's garden' (left panel), and of an elliptic yes-no

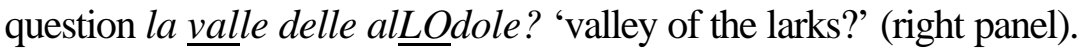


Formally, the two pitch accents are clearly distinct, as detailed measurements performed on the two patterns show. Gili Fivela (2002) performed a study of the alignment and scaling characteristics of the two patterns, exploiting a read speech corpus where the production of the two pitch accents was induced on target words inserted in the final position of left-dislocated topic constituents. In this corpus, the sentences were syntactically marked. Left dislocated constituents were explicitly chosen in order to favour the presence of a low intermediate phrase boundary after both pitch accents (Gili Fivela, 1999). ${ }^{20}$ The broad focus and the narrow (contrastive) focus readings of these syntactically marked sentences induced the presence of the two expected pitch accents (see Figure 20 above). Detailed measurements performed on the two patterns showed that their alignment characteristics are significantly different, although some of the differences are particularly small. Averaging the measurements of three speakers' productions, the peak position urns out to be aligned about $80 \mathrm{~ms}$ earlier in the narrow focus interpretation (108 ms vs. $189 \mathrm{~ms}$ after the syllable onset), while the rise onset is aligned only $24 \mathrm{~ms}$ earlier (1ms vs. $25 \mathrm{~ms}$ from syllable onset). Moreover, in both pitch accents, the peak and the low target position appear not to be affected by changes in the prosodic contexts. On the other hand, only the early peak pattern shows a fall to a low target whose position is close to the peak $(10 \mathrm{~ms}$ before the end of postaccentual syllable onset vs. $133 \mathrm{~ms}$ after it), and, more relevantly, is not affected by the number of postaccentual syllables. Thus, both configurations could be considered as instances of a $\mathrm{L}+\mathrm{H}^{*}$ pitch accent, and, allowing for a tritonal analysis, only the contrastive pitch accent would be analyzed as involving a low trailing tone $\mathrm{L}+\mathrm{H}^{*}+\mathrm{L}$. A schematic representation of the two pitch accents is given in Figure 23. 
(a) rise with peak aligned to end of $\sigma$

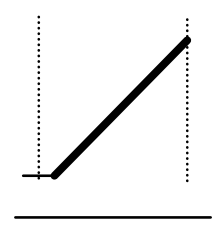

(b) rise with peak early aligned in $\sigma$

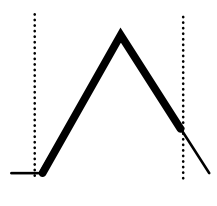

Figure 23. Schematic representation of the two-way contrast in alignment in LH pitch accents in Pisa Italian.

Gili Fivela $(2002,2004)$ proposes considering the low leading tone as a phonetic feature related to the presence of high peaks in Pisa Italian (transcribing it as $[\mathrm{L}+]$ ). The phonological analysis proposed for distinguishing the two pitch patterns is then $\mathrm{H}^{*}$ vs. $\mathrm{H}^{*}+\mathrm{L}$ (while a narrow phonetic transcription would correspond to $[\mathrm{L}+] \mathrm{H}^{*}$ and $\left.[\mathrm{L}+] \mathrm{H}^{*}+\mathrm{L}\right)$. The main argument in favour of such analysis was the observation that taking into account the trailing tone observed in one of the two patterns is enough to phonologically distinguish the two pitch accents, leaving the transcription of the low leading tone for phonetic purposes. As a potential confirmation of a difference between the relevance of leading and trailing tones, a slight difference in stability with respect to syllable composition was observed for the $\mathrm{LH}$ distance rather than for the HL one. Moreover, in spontaneous material, but also depending on the position of the pitch accents in the utterance, the presence of the low leading tone target can be less evident in case of smaller pitch range excursions (Gili Fivela \& D'Imperio 2004). Considering the leading tone as phonetically relevant is in line with these observations, and allows for a more transparent labelling, i.e. the low target is labelled when it is clearly visible at F0 inspection, without postulating a different phonological entity. 
Considering in detail the mapping between phonology and phonetics, the two patterns found in Pisa Italian could be interpreted as instances of high tones primarily associated to the metrically strong syllable, and both secondarily associated to the right edge of the syllable. In this view, the earlier alignment found in one case could be explained by considering the presence of a trailing tone as causing tonal repulsion, i.e. the earlier alignment of the peak. Such a view, though, would force the interpretation that the alignment of the trailing tone with the syllable boundary is relevant for the whole pitch accent. This could be achieved in various ways. One option would be, for instance, to hypothesize that the structure of the contrastive pitch accent is similar to the one proposed by Frota (2002) for the $\mathrm{H}^{*}+\mathrm{L}$ pitch accent in Portuguese, i.e. the $\mathrm{H}$ and $\mathrm{L}$ tones are in a strong-weak relation, but they are both under a strong node. This strong node would then display a secondary association to the right edge of the syllable. Nevertheless, such a proposal has been motivated in Portuguese because of an asymmetric behaviour of leading and trailing tones in $\mathrm{H}+\mathrm{L}^{*}$ and $\mathrm{H}^{*}+\mathrm{L}$ pitch accents. In Pisa Italian, no systematic investigation has been performed on the $\mathrm{H}+\mathrm{L}^{*}$ accent. Nevertheless, there are no reasons to postulate an asymmetric behaviour for such pitch accents, or, better, for the leading tone in comparison to a trailing tone. ${ }^{21}$ In fact, the high leading tone in $\mathrm{H}+\mathrm{L}^{*}$ is aligned before the accented syllable. On the other hand, a $\mathrm{H}^{*}$ can be preceded by a low target in a stable relationship with the starred tone and aligned within the syllable boundary (see discussion above). Thus, proposing that starred tones and trailing tones are both under a strong node - being secondarily associated to the right edge of the syllable -, while leading tones and starred tones are not under the same strong node, does not fit the Pisa Italian data. The proposal might then be applied to any bitonal pitch accent, except that the suggestion that leading tones 
also belong to the same strong node does not fit the data either, since the alignment of high leading tones would not be explained by hypothesizing that the strong node has a secondary association to the left edge of the syllable.

Another option would be to consider that the trailing tone has a secondary association to the right edge of the syllable, either by considering it as a phrase accent secondarily associated to the accented syllable along the lines of proposals by Grice, Ladd \& Arvaniti (2000), Hualde (2002) or Schepman et al. (in press), or by thinking of it as part of the pitch accent along the lines of the proposal argued for in this paper. The idea of considering the trailing tone as a phrase accent secondarily associated to the syllable right boundary and causing the peak leftward repulsion does not fit the Pisa Italian data. In fact, a phrase accent may be realized after both the $[\mathrm{L}+] \mathrm{H}^{*}$ and the $[\mathrm{L}+] \mathrm{H}^{*}+\mathrm{L}$ accents (see above). It would be possible to hypothesize that it gets secondary association to the syllable right boundary only in case of contrastive interpretation. Nevertheless, in that context there are no reasons, so far, for thinking of the peak and the following low tone as two independent tonal events; moreover, measuring the latency of the trailing tone relative to the syllable right boundary in case of $\mathrm{CV}, \mathrm{CVC}$ and CCVC accented syllables, Gili Fivela \& Savino (2003) found that this latency is significantly smaller in open syllables than in closed ones. This result does not appear to be consistent with the idea of a low tone aligned with the syllable right boundary because of secondary association. As mentioned above, another possibility would be that only the trailing tone, as part of the pitch accent, is secondarily associated to the right edge of the syllable. Nevertheless, exploiting secondary association to account for pitch accent alignment appears to be more coherent when related to the star tone than to a trailing one. This view also allows for a more consistent inter-variety (language) 
treatment of the relationship between trailing tones and starred tones (cf. the proposal in $\S 3$ above for rising pitch accents in Catalan, where the trailing tone is clearly realized as a posttonic rise).

The proposal discussed in this paper goes in the direction of a more transparent mapping between phonology and phonetics, and it accounts for all the above observations. Both accents found in Pisa Italian may be seen as characterized by a high tone primarily associated to the metrically strong syllable, and their differences in alignment can be seen as due to secondary association. The high tone in the early peak pattern is secondarily associated to the first mora of the syllable (see Figure 24, right) and is also characterized by a low trailing tone, stably aligned with respect to the starred tone; on the contrary, the high tone in the delayed peak pattern is secondarily associated to the right edge of the syllable (see Figure 24, left). Although stressed syllables are considered as intrinsically bimoraic only in penultimate position (D'Imperio and Rosenthall, 1999), in case of contrastive accent they may also be taken as bimoraic, because of their greater average duration ${ }^{22}$. At this stage of the analysis, we do not know whether the specifics of the pragmatic/phonology interface can allow a Heavy-Light (heavy $=$ bimoraic) trochee to be built as a result of contrastive focus. Nevertheless we hypothesise that accented syllables in focalized constituents become bimoraic, acquiring a mora through phonetic lengthening.

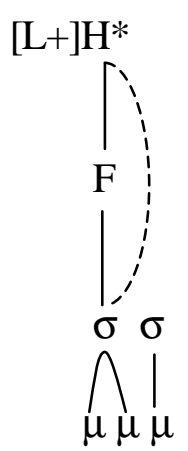

['la va $K$ e lo]

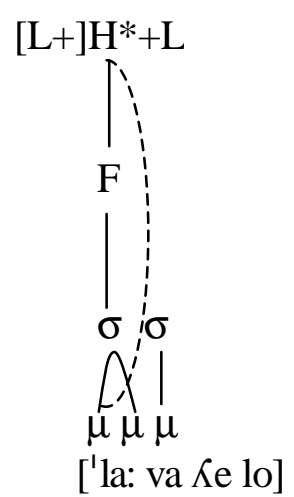


Figure 24. Autosegmental representation of the primary associations of the whole accent (solid lines) and the secondary associations of the individual tone $\mathrm{H}$ to the right edge first mora and to the right edge of the syllable (dashed lines) in rising LH pitch accents in Pisa Italian ( $\omega=$ prosodic word, $F=$ foot, $\sigma=$ syllable, $\mu=$ mora).

This proposal allows a consistent treatment of the two patterns observed in Pisa Italian, directly relating their differences in peak alignment to a difference in secondary association. The two pitch accents, both characterized by a high tone associated to the accented syllable (which is, though, differently aligned within the accented syllable), may both be analyzed as being characterized by primary association of a high tone to the syllable, while differing in secondary association, i.e. to the right edge of the syllable in one case and to the right edge of the first mora in the other.

\section{Conclusion}

The contrastive possibilities of tonal alignment found in three Romance varieties, namely, Central Catalan, Neapolitan Italian and Pisa Italian, have provided crucial evidence that we need to incorporate a notion of phonological anchoring with metrical structure in the phonological representation of tones. This notion is an extension of the secondary association of tones initially proposed in Pierrehumbert \& Beckman (1988). We have argued that by using the notational proposal advanced here, the high or rising accents which are present in these three Romance varieties can be regarded as the same 
choice of a basic tone sequence, namely $\mathrm{LH}$, while differing in details of alignment expressed as choice of anchoring points in the metrical structure.

In our view a more complete phonological encoding of the metrical and anchoring information has advantages for the AM theoretical model. First, as noted by Cole (2000, p. 177), the proposal of alignment to metrical edges and tone features can have the advantage of relating tonal phenomena to segmental phenomena (as is well-known, vowel and consonant harmony systems are bounded by metrical domains). Second, the specification of metrical anchoring points in the phonological representation offers a more transparent analysis of the alignment contrasts found in Romance languages and, ultimately, can help in the task of defining a more transparent pitch-accent typology (along the lines pointed out by Beckman, 2004). Finally, it makes the mapping from phonological representation to surface alignment patterns more explicit and it thus allows for more straightforward crosslinguistic comparisons. 


\section{References}

ANDERSON, A., BADER, M., BARD, E., BOYLE, E., DOHERTY, G., GARROD, S., ISARD, S., KOWTKO, J., MCALliSTER,J., MILlER, J., SOTILlO, C., THOMPSON, H., WEINERT, R. (1991). The HCRC map task corpus. Language and Speech, 34, 4, 351-366.

ARRANZ, P. \& GARRIDO, J. M. (2001). Un estudio perceptivo del desplazamiento del pico acentual en español. Ms. Universitat Autònoma de Barcelona.

ARVANITI, A. \& BALTAZANI, M. (2004). Greek ToBI. In Jun, S.-A. (Ed.), Prosodic Models and Transcription: Towards Prosodic Typology (pp. 84-117). Oxford: Oxford University Press.

ARVANITI, A., LADD, D.R., \& MENNEN, I (1998). Stability of tonal alignment: the case of Greek prenuclear accents. Journal of Phonetics, 26, 3-25.

ARVANITI, A, LADD, D.R., \& MENNEN, I. (2000). What is a starred tone? Evidence from Greek. In M. Broe and J. Pierrehumbert (Eds.), Papers in Laboratory Phonology V: Acquisition and the Lexicon (pp. 119-131). Cambridge: Cambridge University Press.

ATTERER, M. \& LADD, D. R. (2004). On the phonetics and phonology of "segmental anchoring" of F0: evidence from German. Journal of Phonetics 32, 177-197.

BECKMAN, M. (2004). Tone inventories and tune-text alignments. ESF Workshop on Typology of Tone and Intonation. Cascais, Portugal, April 1-3, 2004. [http://ling.osu.edu/ mbeckman/795Tsu2004/typology/]

BECKMAN, M., DÍAZ-CAMPOS, M., McGORY, J.T. \& MORGAN, T.A. (2002). Intonation across Spanish, in the Tones and Break Indices framework. Probus, 14, 9-36. 
BRUCE, G. (1977). Swedish Word Accents in Sentence Perspective. Gleerup: Lund.

CASPERS, J. (1999). The early versus the late accent-lending fall in Dutch: Phonetic variation or phonological difference. In Proceedings of the International Congress of Phonetics Sciences, San Francisco, 945-948.

COLE, J. (2000). Commentary: Integrating the phonetics and phonology of tone alignment. In M. Broe and J. Pierrehumbert (Eds.), Papers in Laboratory Phonology V: Acquisition and the Lexicon (pp. 168-179). Cambridge: Cambridge University Press.

DE LA MOTA, C. (1995). La representación gramatical de la información nueva en el discurso. Ph.D. Dissertation, Universitat Autònoma de Barcelona.

D'IMPERIO, M. (1995). Timing differences between prenuclear and nuclear pitch accents in Italian, Journal of the Acoustical Society of America 98(5), 28-94.

D'IMPERIO, M. and HOUSE, D. (1997). Perception of Questions and Statements in Neapolitan Italian, Proceedings of Eurospeech '97, vol.1, 251-254.

D'IMPERIO, M. and S. ROSENTHALL (1999). Phonetics and phonology of main stress in Italian, Phonology, 16(1), 1-28.

D'IMPERIO, M. (2000). The Role of Perception in Tonal Targets and their Alignment. Ph.D. Dissertation, Ohio State University [http://www/lpl.univaix.fr/lpl/documents/theses/mpthesis.pdf].

D'IMPERIO, M. (2001). Focus and tonal structure in Neapolitan Italian, Speech Communication, 33(4), 339-356.

D'IMPERIO, M. (2002a). Italian intonation: an overview and some questions. Probus, 14, 37-69. 
D'IMPERIO, M. (2002b). Language-Specific and Universal Constraints on Tonal Alignment: The Nature of Targets and 'Anchors'. In B. Bel and I. Marlien (Eds.) Proceedings of Speech Prosody 2002, 101-106.

D'IMPERIO, M. (2003). Tonal structure and pitch targets in Italian focus constituents, Catalan Journal of Linguistics, 2 (Special volume on Romance Intonation, ed. by P. Prieto), 55-65.

D'IMPERIO, M. (submitted). Question identification in Italian and English: The interplay between tonal alignment and pitch height, Phonetica (special issue on "Progress in Experimental Phonology : From communicative function to phonetic substance and vice versa", ed. by K. Kohler).

ELORDIETA, G. (1998). Intonation in a pitch accent variety of Basque. International Journal of Basque Linguistics and Philology, ASJU, 32, 511-569.

ESTEBAS-VILAPLANA, E. (2000). The Use and Realisation of Accentual Focus in Central Catalan. Ph. D. Dissertation, University College London.

ESTEBAS-VILAPLANA, E. (2003). Catalan Pre-Nuclear Accents: Evidence for WordEdge Tones. In M. J. Solé, D. Recasens and J. Romero (Eds.), Proceedings of the XVth International Congress of Phonetic Sciences (pp. 1779-1782). Barcelona: Causal Productions.

FACE, T. (2001a). Intonational marking of contrastive focus in Madrid Spanish. Ph.D. Dissertation, Ohio State University. Published by Lincom Europa, 2002.

FACE, T. (2001b). Focus and early peak alignment in Spanish intonation. Probus 13, 223-246.

FROTA, S. (2000). Prosody and focus in European Portuguese. Phonological phrasing and intonation. New York: Garland Publishing. 
FROTA, S. (2002). Tonal association and target alignment in European Portuguese nuclear falls. In C. Gussenhoven and N. Warner (Eds.), Papers in Laboratory Phonology VII (pp. 387-418). The Hague: Mouton de Gruyter.

FROTA, S. (2003). The phonological status of initial peaks in European Portuguese, Catalan Journal of Linguistics, 2 (Special volume on Romance Intonation, ed. by P. Prieto), 133-152.

GILI FIVELA, B. (1999). The prosody of left-dislocated topicalized constituents in Italian read speech. In Proceedings of the European Conference on Speech Communication and Technology 1, Budapest, Hungary, pp. 531-534.

GILI FIVELA, B. (2002). Tonal Alignment in two Pisa Italian peak accents. In B. Bel and I. Marlien (Eds.), Proceedings of the Speech Prosody 2002 Conference (pp. 339-342), Aix-en-Provence.

GILI FIVELA, B. (2004). The phonetics and phonology of intonation: the case of Pisa Italian. Ph D. Dissertation, Scuola Normale Superiore, Pisa.

GILI FIVELA, B. \& D'IMPERIO, M. (2004). Tonal alignment of prenuclear accents in Italian: a study on the varieties spoken in Pisa and Naples. ESF International Conference on Tone and Intonation. Santorini (Greece), September 9-11, 2004.

GILI FIVELA, B. \& SAVINO, M. (2003). Segments, syllables and tonal alignment: A study on two varieties of Italian. Proceedings of the XVth International Conference of Phonetic Sciences, Barcelona, Spain, 3-9 August 2003, pp. 29332936.

GOLDSMITH, J. (1979). Autosegmental Phonology. Garland, New York - PhD thesis 1976. 
GRICE, M. \& BENZMÜLLER, R. (1995). Transcription of German Intonation using ToBI-Tones - The Saarbrücken system. In W. J. Barry and J. Koreman (Eds.), PHONUS, 1, pp. 35-52.

GRICE, M., BAUMAN, S., BENZMÜLLER, R. (2005a). German intonation in autosegmental-metrical phonology. In Jun, S.-A. (Ed.). Prosodic Models and Transcription: Towards Prosodic Typology (pp. 55-83). Oxford: Oxford University Press.

GRICE, M., D’IMPERIO, M., SAVINO, M. \& AVESANI, C. (2005b). Towards a strategy for labelling varieties of Italian. In Jun, S.-A. (Ed.), Prosodic Models and Transcription: Towards Prosodic Typology (pp. 55-83). Oxford: Oxford University Press.

GRICE, M. (1995). The intonation of Palermo Italian: implications for intonation theory. Tübingen: Niemeyer.

GRICE, M., LADD, D.R., \& ARVANITI, A. (2000). On the place of phrase accents in intonational phonology, Phonology, 17, 143-185.

GODJEVAC, S. (2000). An autosegmental/metrical analysis of Serbo-Croatian intonation. Ohio State University Working Papers in Linguistics, 54: 79-142.

GUSSENHOVEN, C., RIETVELD, T, \& TERKEN, J. (1999). ToDI: Transcription of Dutch Intonation. [http://lands.let.kun.nl/todi]

GUSSENHOVEN, C. \& VAN DER VLIET (1999). The phonology of tone and intonation in the Dutch dialect of Venlo. Journal of Linguistics, 35, 99-135.

GUSSENHOVEN, C. \& KERKHOFF, J. (2001). The synthesis of Dutch intonation on the basis of ToDI labels. Workshop on Tone and Intonation in Europe, VitoriaGasteiz, June 2001. 
GUSSENHOVEN, C. (2000). The boundary tones are coming: on the nonperipheral realization of boundary tones. In M. Broe and J. Pierrehumbert (Eds.), Papers in Laboratory Phonology V: Acquisition and the Lexicon (pp. 132-151). Cambridge: Cambridge University Press.

GUSSENHOVEN, C. (2004). The phonology of tone and intonation. Cambridge: Cambridge University Press.

HIRSCHBERG, J. \&. WARD, G. (1992). The influence of pitch range, duration, amplitude and spectral features on the interpretation of the rise-fall-rise intonation contour in English, Journal of Phonetics, 20, 241-251.

HIRST, D. (1983). Structures and categories in prosodic representations. In A. Cutler A. and D.R. Ladd (Eds.). Prosody: models and measurements (pp. 93-109). Berlin, Germany: Springer-Verlag.

HUALDE, J.I. (2002). Intonation in Spanish and the other Ibero-Romance languages: overview and status quaestionis. In C. Wiltshire and J. Campos (Eds.). Romance phonology and variation. Selected papers from the $30^{\text {th }}$ Linguistic Symposium on Romance Languages (pp. 101-116). Amsterdam: John Benjamins.

HUALDE, J.I. (2003a). Remarks on the diachronic reconstruction of intonational patterns in Romance with special attention to Occitan as a bridge language. Catalan Journal of Linguistics, 2 (Special volume on Romance Intonation, ed. by P. Prieto), 181-205.

HUALDE, J. I. (2003b). El modelo métrico y autosegmental. In Prieto, P. (Ed.), Teorías de la entonación (pp. 155-184). Barcelona: Editorial Ariel.

JUN, S.-A. \& FOUGERON, C. (2000). A phonological model of French intonation. In A. Botinis (Ed.), Intonation: analysis, modelling and technology (pp. 209-242). Boston: Kluwer. 
LADD, D.R. (1983). Phonological features of intonational peaks. Language, 59, 721759.

LADD, D.R. (1994). Constraints on the gradient variability of pich range, or, Pitch level 4 lives!. In P. A. Keating (Ed.), Phonological Structure and Phonetic Form. Papers in Laboratory Phonology III (pp. 43-63), Cambridge University Press: Cambridge, Massachusetts.

LADD, D. R. (1996). Intonational phonology, Cambridge University Press, Cambridge.

LADD, D. R. (2004). Segmental anchoring of pitch movements: autosegmental phonology or speech production? In Quene, H. and V. van Heuven (Eds.), On Speech and Language: Studies for Sieb G. Nooteboom (pp. 123-131). Utrecht: Netherlands Graduate School of Linguistics (LOT).

LADD, D. R. \& SCHEPMAN, A. (2003). Sagging transitions between high pitch accents in English: experimental evidence, Journal of Phonetics 31, 81-112.

LIBERMAN, M. (1975). The Intonational System of English. Ph. D. Dissertation, Massachussetts Institute of Technology. Published by Garland Publishing, 1979.

MAROTTA, G. (2000). Allineamento e trascrizione dei toni accentuali complessi: una proposta. Atti delle 10e Giornate di Studio del Gruppo di Fonetica Sperimentale, Collana degli Atti dell'Associazione Italiana di Acustica., vol. XXVII, Napoli 2000, pp. 139-149

PIERREHUMBERT, J. B. (1980). The Phonology and Phonetics of English Intonation. Ph.D. Dissertation, Massachusetts Institute of Technology.

PIERREHUMBERT, J., \& BECKMAN, M. (1988). Japanese Tone Structure. Cambridge, Massachusetts: The MIT Press.

PIERREHUMBERT, J. B. \& STEELE, S. (1989). Categories of Tonal Alignment in English, Phonetica, 46, 181-196. 
PRIETO, P.; VAN SANTEN, J. \& HIRSCHBERG, J. (1995). Tonal Alignment Patterns in Spanish. Journal of Phonetics, 23, 429-451.

PRIETO, P. (1998). The Scaling of the L Tone Line in Spanish Downstepping Contours, Journal of Phonetics, 26, 261-282.

PRIETO, P (2002a). Entonació. In Solà, J., M.-R. Lloret, J. Mascaró and M. PérezSaldanya (Eds.), Gramàtica del català contemporani (pp. 393-462). Barcelona: Editorial Empúries.

PRIETO, P. (2002b). Entonació: Models, teoria, mètodes. Barcelona: Ariel

PRIETO, P. (2003). The representation of rising accents in Catalan and Spanish. Workshop on Intonation in language varieties, Satellite Meeting to the $15^{\text {th }}$ International Congress of Phonetic Sciences, Barcelona, August 3, 2003.

PRIETO, P. (2004a). The Search for Phonological Targets in the Tonal Space: Evidence from Five Sentence-Types in Peninsular Spanish. In T. Face (Ed.), Laboratory Approaches to Spanish Phonology (pp. 29-59). The Hague: Mouton de Gruyter.

PRIETO, P. (2004b). Catalan Intonation within a Romance Perspective. ESF Workshop on Typology of Tone and Intonation. Cascais, Portugal, April 1-3, 2004.

PRIETO, P. (forthcoming a). Stability effects in tonal clash contexts in Catalan. Journal of Phonetics.

PRIETO, P. (forthcoming b). En torno a la asociación tonal en el modelo métricoautosegmental. Puntos controvertidos en su aplicación al catalán. Revista Internacional de Lingüística Iberoamericana 3.2 (Special issue on Prosodic Aspects, ed. by Johannes Kabatek).

PRIETO, P. (submitted). Word-Edge Tones in Catalan. Italian Journal of Linguistics 17 (Special Issue on Autosegmental-Metrical Approaches to Intonation in Europe: Tonal Targets and Anchors, ed. by M. D'Imperio) 
PRIETO, P. \& TORREIRA, F. (2004). Anchoring Effects in Spanish. ESF International Conference on Tone and Intonation. Santorini (Greece), September 9-11, 2004.

SCHEPMAN, A.; LICKLEY, R. \& LADD, D.R. (in press). Effects of vowel length and "right context" on the alignment of Dutch nuclear accents, Journal of Phonetics

SILVERMAN, K. \& PIERREHUMBERT, J. (1990). The timing of prenuclear high accents in English. In Papers in Laboratory Phonology I. Between the Grammar and Physics of Speech, J. Kingston and M. E. Beckman (eds). Cambridge: Cambridge University Press, 72-106.

SMILJANIC, R. (2002). Lexical, pragmatic and positional effects on prosody in two dialects of Croatian and Serbian: An acoustic study. $\mathrm{PhD}$. Dissertation, University of Illinois at Urbana-Champaign.

SMILJANIC, R. (forthcoming). Early vs. late focus: pitch-peak alignment in two dialects of Serbian and Croatian. In Papers in Laboratory Phonology 8. Yale University and Haskins Laboratories, USA.

SMILJANIC, R. \& HUALDE, J.I. (2000). Lexical and pragmatic functions of tonal alignment in two Serbo-Croatian dialects. In A. Okrent and J. Boyle (Eds.), Chicago Linguistic Society 36, vol. 1, The Main Session (pp. 469-482). Chicago: Chicago Linguistic Society.

SOSA, J. M. (1999). La entonación del español. Barcelona: Cátedra.

TOLEDO, G. (2003). Modelo autosegmental y entonación: los corpus DIES-RTVP, Estudios de Fonética Experimental, 12, 143-163.

VERHOEVEN, J. (1994). The discrimination of pitch movement alignment in Dutch. Journal of Phonetics, 22, 65-85. 
VIGÁRIO, M. \& FROTA, S. (2004). The intonation of Standard and Northern

European Portuguese: A comparative intonational phonology approach. Journal of

Portuguese Linguistics, 2-2. 115-137.

WARD, G. \& HIRSCHBERG, J. (1985). Implicating uncertainty. The pragmatics of fall-rise intonation. Language, 61, 747-776.

WELBY, P. (2003). The slaying of Lady Mondegreen, being a study of French tonal association and alignment and their role in speech segmentation. $\mathrm{PhD}$ Dissertation, The Ohio State University.

WELBY, P. (2004). The Structure of French Intonational Rises: A Study of Text-toTune Alignment. In B. Bel and I. Marlien (Eds.), Proceedings of the Speech Prosody 2004 Conference (pp. 127-130). Nara, Japan.

\footnotetext{
${ }^{1}$ We would like to make clear right from the start that we will be describing categorical differences among pitch accents, not phonetic implementation differences. Generally, the criteria we will use to know that a categorical effect is in place is the use of a different pitch accent for a difference in meaning. In some cases, like in Neapolitan Italian, we will be able to resort to perceptual evidence that shows that listeners do interpret the semantic difference between accents categorically. This does not imply to say that accents are phonetically realized in a stable way: as it is well-known, we do acknowledge that phonetic differences are sensitive to prosodic context and can also express paralinguistic meaning differences.

${ }^{2}$ By posttonic rise we mean a rise that is produced in the syllable after the accented syllable.

${ }^{3}$ Face (2001a) provided crucial evidence that the $\mathrm{H}$ peak in nuclear accents was aligned with the right edge of the accented syllable even in proparoxitonic words, a context in which the pressure from the final L boundary tone is not active. In Peninsular Spanish, utterance-initial accents of commands, exclamatory utterances, and contrastive focus utterances are instances of $\mathrm{L}+\mathrm{H}^{*}$ and utterance-initial accents of statements and questions are instances of $\mathrm{L}^{*}+\mathrm{H}$ (cf. de la Mota 1995, Face 2001a, 2001b, Prieto 2004a).
} 
4 Marotta 2000) has a somewhat similar proposal for the representation of Italian accents. Marotta proposes to label as $(\mathrm{L}+\mathrm{H})^{*}$ or $(\mathrm{H}+\mathrm{L})^{*}$ and, conversely, $(\mathrm{L}+\mathrm{H})$ or $(\mathrm{H}+\mathrm{L})$ those cases where both and none targets are aligned with the stressed syllable. These patterns alternate with more transparent ones, where the star is actually transcribed after the tone which is aligned to the syllable. In her proposal, then, the star would then correspond to alignment, and the two pitch accents would represent allophonic variants of the same pattern.

${ }^{5}$ Hualde (2003b) also notes that similar intonation systems (e.g., standard English and Dutch) can receive very different analyses (e.g., compare the English ToBI transcription system proposed by M. Beckman, J. Pierrehumbert and collaborators with the proposal by C. Gussenhoven in ToDI for Dutch). Even though the two systems are quite similar, very different analyses are given for the same intonation contours. The following figure illustrates the transcription differences between ToBI and ToDI of the same utterance 'It doesn't need to be a disaster'. Gussenhoven \& Kerkhoff (2001) present a detailed comparative work of the AM transcriptions in both languages.

$\underline{\text { Dutch }}$

ToDI

ToBI

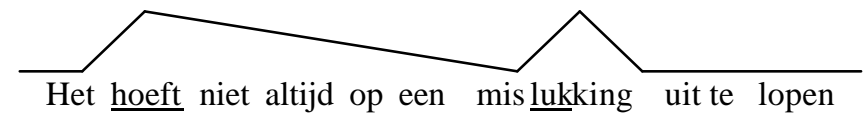

$\% \mathrm{~L} \mathrm{H} \mathrm{H}^{*} \mathrm{~L}$

$\mathrm{H}^{*} \mathrm{~L}$

$\mathrm{L}+\mathrm{H}^{*}$

$\mathrm{L} \%$

$\mathrm{H}^{*}$

$\mathrm{L}-\mathrm{L} \%$

'It needn't always end in failure'

\begin{abstract}
${ }^{6}$ As Gorka Elordieta points out (p.c.), it is plausible that the second pitch accent in the sentence (on $\underline{n e n a)}$ can be interpreted as a posttonic rise too. In this case, we interpret this pitch accent as a $\mathrm{L}^{*}$ tone followed by a high rise $\mathrm{H}-\mathrm{H} \%$. The difference between the first and the second pitch accents is the absence vs. presence of a phrase boundary after the pitch accent, respectively.

${ }^{7}$ See also the shape of the other prenuclear pitch accent associated to the verb vol, which has a delayed peak located in the posttonic syllable.

${ }^{8} \mathrm{We}$ do acknowledge that the right-hand prosodic context such as the presence of an upcoming pitch accent or boundary tone can affect the $\mathrm{H}$ target alignment (Silverman \& Pierrehumbert 1989; Prieto et al 1995 for Spanish; and Prieto forthcoming a for the effects of clash on rising accents in Catalan). And even in contexts that are not tonally crowded, some degree of variability is expected (see Prieto \& Torreira 2004 for Spanish). Yet, it is important to make clear that the contrasts in Figure 11 work irrespective of the constraints on alignment due to upcoming tonal events and/or boundaries, that is, they are not neutralised.
\end{abstract}

${ }^{9}$ As pointed out by J. I. Hualde (p.c.), the perceptual procedure of assigning a star to either L or H is the same procedure used by Bantu tonologists. In this tradition, each syllable is labeled either $\mathrm{H}$ or $\mathrm{L}$ depending on the perception of the syllable as high or low. Yet, at the surface level, $\mathrm{H}$ will be either realized as a rising tone or a high pitch plateau and $\mathrm{L}$ as a falling tone or a low pitch plateau. For example, in something transcribed as òmúkálí múnènè /LHHH HLL/ the first $\mathrm{H}$ is phonetically realized as a rising tone and the second $\mathrm{H}$ as a high plateau. The same is true of the $\mathrm{L}$ values: while the penultimate $\mathrm{L}$ is phonetically realized as a falling tone, the last $\mathrm{L}$ will be realized as a plateau. Of course, as pointed out by B. Ladd, morphophonological and cross-linguistic evidence is also taken for positing one tone or the other on a given syllable. In our view, the decision about assigning either $\mathrm{H}$ or $\mathrm{L}$ in Bantu languages is based on two pieces of information: (a) the perceptual entity of the tone, that is, whether it is perceived as $\mathrm{H}$ or as L; (b) paradigmatic arguments and morphological analysis: that is, indeed, in some cases a tone that is perceived as $\mathrm{H}$ for paradigmatic reasons is given an $\mathrm{L}$ label.

${ }^{10}$ As pointed out by Gorka Elordieta (p.c.), the nuclear pitch accent in the wh-question starts falling not at the end of the syllable itself, but some time before it. We should further investigate the behavior of this pitch accent in other accentual patterns and determine whether the fall starts earlier due to the presence of 
upcoming boundary tones LL\% or the precise timing of the start of the fall is part of the phonetic realization of the accent itself.

11 As Pierrehumbert and Beckman (1988: 159) claim, "the left-peripheral, central, and right-peripheral alignments cannot be distinguished by the association relation alone. If it is desirable to distinguish them - for instance to describe the relative timing of elements on different tiers that are attached to the same node - this must be done by additional stipulations. In cases with which we are familiar such stipulations take the form of language-specific rules of phonetic interpretation." In principle, as the authors suggest, if we discovered cases in which "alignment is contrastive within a language, these might be handled by the use of an alignment feature on the prosodic nodes or on the substantive elements.

${ }^{12}$ As we pointed out before, even with tones that obligatorily align to edges (for example, the right edge of the syllable) some degree of variability is expected. Thus, by performing measurements, one should not expect a perfect alignment between the peak and the offset of the syllable, but rather small differences across speakers. We should note that in the three Romance varieties studied in this article, some speakers produced the 'aligned' peak right after the offset and some speakers right before it. As Bob Ladd (p.c.) points out, this analysis should entail a prediction of greater variance in alignment data for tones that do not have secondary association. In fact, we count on preliminary evidence from Catalan and Spanish that reveals that $\mathrm{H}$ tones that have a secondary alignment to the right edge of the syllable are more stable in alignment than those that belong to accents with no secondary associations, namely, accents with delayed peaks or posttonic rises (see Prieto \& Torreira 2004, Estebas-Vilaplana 2000). Yet, whether this prediction is borne out is still an empirical question that should be investigated in greater detail.

13 This example was brought out to our attention by José Ignacio Hualde. As Ladd (p.c) points out, the Serbo-Croatian data suggest that the $\mathrm{H}$ peak of "rising" accents can drift off as much as two syllables to the right of the accented syllable. Maybe both accents can be interpreted as LH, but the $\mathrm{H}$ is secondarily associated (e.g. to the edge of the stres sed syllable) in the "falling" accent and not secondarily associated in the "rising" accent. We believe it is worth exploring the complex contrastive alignment patterns found in Serbo-Croatian in the light of the present proposal, even though this goes beyond the scope of the present paper. Recent work on Serbo-Croatian accent and intonation includes Godjevac (2000), Smiljanic $\&$ Hualde (2000) and Smiljanic (forthcoming).

14 As we can see in Figure 17, early focus questions (right panel) are characterized by a postfocal, downstepped H accent (D'Imperio 2001) which is not perceived as the most prominent (nuclear) accent in the phrase.

15 Despite the observable pitch level difference in the prenuclear stretch of the question and statement utterances, mainly due to the lower level reached by the starred $\mathrm{L}$ of the question $\mathrm{L}^{*}+\mathrm{H}$, this difference does not seem to play a role in perception (D'Imperio, 2000), hence is not phonologically encoded. As to the difference in the postnuclear stretch, this is due to the presence of a postfocal accent $\left(\mathrm{H}^{*}\right)$ only in the question utterance (D'Imperio, 2001, 2002a). Again, the presence of such an event is not necessary in order for a question pitch accent to be correctly identified as such.

16 There seems to be some evidence that the pitch accent is actually associated to a higher level domain, such as the prosodic word (see D'Imperio, 2002a), but we are not going to discuss this possibility here.

${ }^{17}$ Informal listening by Pisa speakers of instances of the two pitch accents showed that they are both perceived as (mainly) high, although they differ. Nevertheless a formal perception test should be performed in order to confirm the hypothesis on the auditory characteristics of the two patterns.

${ }^{18}$ In case of contrastive interpretation of the utterance, no resumptive clitic is produced.

${ }^{19}$ In Map-Task dialogues, instruction givers are given a map with a path among icons drawn on it, while instruction followers are only given a map with icon names. The task consists of communicating verbally to reconstruct the path on the map lacking it (Anderson et al., 1991).

${ }^{20}$ Defining the nuclear pitch accent as the last one in an intermediate phrase, both pitch accents are nuclear and followed by a low phrase accent (Pierrehumbert \& Beckman, 1986). 
${ }^{21}$ Unfortunately, no $\mathrm{L}^{*}+\mathrm{H}$ accent is present in the tonal inventory of Pisa Italian for comparison.

${ }^{22}$ Duration measurements of accented syllables showed that, even collapsing data across syllable position in the word, they are 7 to 10 percent longer in contrastive than in broad focus interpretation (see Gili Fivela, 2004). The duration difference is significant $([\mathrm{F}(1,648)=93,742 ; \mathrm{p}<0,001])$, and does not interact with syllable position within the word $([\mathrm{F}(2,647)=1,420 ; \mathrm{p}>0,05])$. Thus, syllables bearing a contrastive accent are significantly longer, irrespective of their position within the word (compare, for instance, accented syllable lengthening in the utterances shown in Figure 20). 